\title{
Comparison between Cabergoline and Coasting in Prevention of Ovarian Hyperstimulation Syndrome and their effect on Intracytoplasmic Sperm Injection Outcome
}

\author{
Ismaeil M. El-Garhy , Ahmed O. Abdel Motaal, Mohamed G. Omr \\ Department of Obstetrics and Gynecology \\ Faculty of Medicine, Al Azhar University \\ Corresponding author: Mohamed Gamal ,email:mohamedgamalomer90@gmail.com,Mobile : 01091133258
}

\begin{abstract}
Aim of the work: ovarian hyperstimulation syndrome (OHSS) is an iatrogenic, serious and potentially fatal complication of ovarian stimulation, affecting1-14\% of all IVF/ICSI cycles. This study aimed to compare cabergoline after hCG administration with delayed hCG administration (coasting) in high risk patients to prevent OHSS in ART cycles. Patients and methods: this prospective comparative randomized study included 100 patients at risk of OHSS performed in the Assisted Reproductive Technologies Center, AlAzhar University and in Private IVF Centers during the period from November, 2015 to October, 2016. Results: comparison between the two groups showed no significant difference regarding age, BMI, presence of risk factors of OHSS, but there was a significant difference regarding FSH, LH and the mean diameter of follicles on day of hCG administration. Conclusion: PCOS affects 5 to $10 \%$ of women of childbearing age and is the most common cause of anovulatory infertility in developed countries. Recommendations: further studies including large number of cases and for longer duration will further confirm the efficacy of cabergoline and coasting on prevention of OHSS.
\end{abstract}

Keywords: Cabergoline, Coasting, Ovarian Hyperstimulation Syndrome, Intracytoplasmic Sperm Injection Outcome.

\section{INTRODUCTION}

WHO defines infertility as follows: infertility is the inability to conceive a child. A couple may be considered infertile if, after two years of regular sexual intercourse, without contraception, the woman has not become pregnant (and there is no other reason, such as breastfeeding or postpartum amenorrhoea).

Primary infertility: is infertility in a couple who have never had a child.

Secondary infertility: is failure to conceive following a previous pregnancy. Infertility may be caused by infection in the man or woman.

\section{Causes of Infertility:}

- Male factors $30 \%$.

- Female factors $30 \%$.

- Combined $10 \%$

- Unexplained $25 \%$.

- Others 5\%

Polycystic ovary syndrome is a clinical diagnosis characterized by the presence of two or more of the following features: chronic oligoovulation or anovulation, androgen excess and polycystic ovaries. It affects 5 to $10 \%$ of women of childbearing age and is the most common cause of anovulatory infertility in developed countries. Common clinical manifestations include menstrual irregularities and signs of androgen excess (such as hirsutism, acne, and alopecia ${ }^{(\mathbf{1})}$.

Polycystic ovary syndrome is a heterogeneous clinical syndrome, which has been defined as the association of hyper androgenism with chronic an ovulation in women without specific adrenal and pituitary gland disease. A family history of polycystic ovary syndrome may be present in a subset of patients, however, the genetic basis of the syndrome remains unclear. Most often, the age of onset is perimenarchal and it is characterized by the appearance of menstrual disturbances, hirsutism, acne, and more rarely and male pattern of alopecia. Polycystic ovary syndrome is also associated with metabolic disturbances, such as obesity and insulin resistance with hyperinsulinemia ${ }^{(2)}$.

ICSI is a laboratory procedure in which one or more eggs (oocytes) are retrieved. Fertilization is achieved by the injection of individual sperm into each egg ${ }^{(3)}$.

Implantation is the final and the most crucial step in intra cytoplasm sperm injection (ICSI) and in vitro fertilization (IVF), however it is the least successful, as a few embryos replaced in the uterine cavity will result in clinical pregnancy. The majority of women undergoing IVF will reach the embryo transfer (ET) stage, with good quality embryos available for transfer, but only a small proportion of them will ever achieve a clinical pregnancy or live birth. Up to $85 \%$ of the embryos replaced into the uterine cavity will fail to implant this makes the ET procedure a highly vital, but an inefficient step in IVF $^{(4)}$.

In 1989, a study carried out by Englert $\boldsymbol{e t}$ al. ${ }^{(5)}$ reported a $33.3 \%$ pregnancy rate with 
transfers rated excellent, where bad transfers yielded only a $10.5 \%$ pregnancy rate.

The pregnancy rate after ET is dependent on multiple factors including embryo quality, endometrial receptivity and the technique of the ET itself. Consequently, any modification to the standard protocol that will improve the outcome is of great value. The research on IVF is abundant, but relatively little study and attention has been directed by the ET technique ${ }^{(\boldsymbol{6})}$.

Cabergoline, a dopamine agonist inhibits VEGFR-2 phosphorylation and signalling, effectively reduced the incidence of OHSS and cycle cancellation without any adverse effects on pregnancy. The findings of the present study are in agreement with those of a previous study ${ }^{(7)}$.

Ovarian hyperstimulation syndrome, as a potentially life-threatening situation and the most serious complication of assisted reproduction treatment, is regarded as an iatrogenic complication which must be avoided and in case of occurrence its severity must be reduced ${ }^{(8)}$.

Considering the physical and psychological consequences along with medical costs like hospitalization, every intervention to decrease VEGF expression or antagonizing its effects would be valuable ${ }^{(8)}$.

The ovary is the main source of cytokines and VEGF, which are mediators that cause increased capillary permeability and ascites. It has been suggested that parameters of ovarian activity during stimulation such as serum levels of estradiol and number of oocytes retrieved correlate closely with VEGF gene expression ${ }^{(8)}$.

This is a prospective study performed to compare cabergoline after hCG administration with delayed hCG administration (coasting) in highrisk patients to prevent OHSS in ART cycles.

\section{PATIENTS AND METHODS}

The study design:

Prospective, randomized controlled study including 100 patients.

\section{Ethical consideration:}

This studied protocol approved by the Local Ethics Committee and written informed consents obtained before the study started.

\section{Location and duration of the study:}

This prospective comparative randomized study included 100 patients at risk of OHSS performed in the Assisted Reproductive Technologies Center, Al-Azhar University during the period from September , 2017 to august, 2018.

High risk patients are defined as young females, who had antral follicle counts of more than 15 , poly cystic ovaries on ultrasound scan and/or polycystic ovarian syndrome (PCOS), serum estradiol of more than 2500 picogram per milliliter $(\mathrm{pg} / \mathrm{ml})$ and/or multiple follicular recruitments in both ovaries during ultrasound monitoring in controlled ovarian hyperstimulation $(\mathrm{COH})$ (More than 20 follicles $>12$ millimeter $(\mathrm{mm})$ on the $10^{\text {th }}$ day of the cycle).

\section{Inclusion criteria}

Women only included in this trial when they had the following criteria:

- The age of 18-35 years, high risk age of developing OHSS.

- Patient had antral follicles count more than 15 follicles.

- PCOS on U/S scanning.

- Body mass index ranging 25-35.

- Polycystic ovarian syndrome was diagnosed according to Rotterdam criteria. According to the Rotterdam criteria, patients with two of the three characteristics including: 1) oligomenorrhea/ amenorrhea, 2) clinical (hirsutism) finding of hyperandrogenism, or 3) polycystic ovaries on transvaginal sonography, included in the study ${ }^{(9)}$.

Metabolic features of PCOS patients not of concern in this study; therefore, insulin resistance and androgen index were not measured.

- Presence of at least 20 follicles in both ovaries during the induction protocol.

- The majority of the follicles being $<14 \mathrm{~mm}$ in diameter.

- Serum E2 level 3000pg/ml.

\section{Exclusion criteria}

Patients excluded if they have: Include patients in whom the use of dopamine agonists is contraindicated:

- History suggestive of cardiovascular diseases.

- Hypersensitivity to ergot derivatives.

- Severely impaired liver functions or cholestasis.

- Peripheral vascular diseases as Raynauds disease.

- Active gastrointestinal bleeding or Gastro duodenal ulcers.

- Hypotention.

In the case, clinical signs such as abdominal pain, nausea, vomiting or distinctly enlarged ovaries $(>12 \mathrm{~cm})$ seen during the days of hCG administration or egg retrieval, or if the serum estradiol level higher than specified $(>6000 \mathrm{pg} / \mathrm{mL})$, either the cycle cancelled or the embryos frozen, according to the physician's opinion and patient's. 
The investigation protocol:

All patients were subjected to:

\section{-Complete history taking:}

Including menstrual history with determination of menarche, regularity of the cycle (amenorrhea or oligomenorrhea), history of endocrine diseases also history of previous operations with special concern to IVF treatment and occurrence of OHSS.

\section{-Physical examination: \\ General examination:}

Special concern to acne, hirsutism, obesity.

$>$ Abdominal examination: for scar of previous pelviabdominal operations and determination of enlarged uterus.

> Pelvic examination: vaginal examination for enlarged uterus and enlarged cystic ovaries.

Patient's characteristics of age in years, height in centimeters, weight in killograms and gravidity were recorded.

\section{Protocol treatment}

All patients were on long protocol starting gonadotrophin releasing hormone analogue $(\mathrm{Gn} \mathrm{Rh})$ on mid luteal phase of the proceeding menstrual cycle.

In order to suppress the pituitary gland a gonadotropin releasing hormone $\mathrm{GnRH}$ agonist (Buserelin, Suprefact $®$, Hoechst, Germany) administered at a subcutaneous dose of $0.5 \mathrm{~mL} /$ day on day 21 of the menstrual cycle. Vaginal ultrasonography done on day 2 or 3 of the next menstrual cycle to confirm absence of any functional ovarian cyst larger than $10 \mathrm{~mm}$. Gonadotropin stimulation consisted of 2-3 ampoules per day of FSH (r-hFSH, Gonal-F®, 75 UI, Serono, Switzerland) for the first 5-7 days. Dose adjustment (increase of 37.5 - 75 UI of $r$ FSH) depended on the individual response to treatment. In the first group, when the number of follicles exceed 20 with at least two being $18 \mathrm{~mm}$ in size, $10000 \mathrm{U}$ of hCG (Pregnyl®), Iran, under Technical Cooperation with Organon) administered intramuscularly and oral cabergoline $0.5 \mathrm{mg} /$ day started immediately and continued for ten days. Egg retrieval performed 36 38 hours after hCG administration. In the second group, when the number of follicles were 20 or more and the mean leading follicle diameter being $16-\mathrm{mm}$, gonadotropin administration ceased and Suprefact continued according to protocol. Serum estradiol level was checked every 48 hours until it became $<3000 \mathrm{pg} / \mathrm{mL}$, after which 10000 units of hCG administered intramuscularly and oocyte pick-up performed after 36-38 hours. After oocyte retrieval and intra cytoplasmic sperm injection (ICSI) procedure, embryo transfer was done trans-cervically
48-72 hours after egg retrieval for both groups. About 2-3 embryos transferred depending on the patient's age and the quality of the embryos. The participants were randomized allocated in two groups:

\section{The first group (cabergoline group):}

Comprised 50 women treated with $0.5 \mathrm{mg}$ of cabergoline (Dostinex®, Pharmacia Italia S.P.A, Italy) every day for 10 days commencing on the day of hCG administration. If OHSS occurred, the standard conservative and supportive management for OHSS be employed.

The second group (coasting group):

Comprised 50 women which were similar to the former group. Gonadotropin administration ceased when 20 follicles or more are scanned on U/S and the leading follicle diameter being $16 \mathrm{~mm}$, until serum estradiol levels reached below $3000 \mathrm{pg} / \mathrm{mL}$ before hCG administration.

All OHSS patients properly followed up and the diagnosis of OHSS as well as its severity performed according to a standard definition. The standard classification categorizes the disease based on its severity to mild, moderate, and severe OHSS. In mild OHSS, patients often report mild abdominal distention and soreness, nausea, vomiting, and ovarian enlargement between 5 to $12 \mathrm{~cm}$. Moderate diseases is characterized by the presence of abdominal ascites on ultrasound examination. Severe diseases is diagnosed when there are clinical signs of tense ascites, hydrothorax, shortness of breath, hemoconcentration, hypercoagulability, or any complications of OHSS such as renal failure, thromboembolism, or acute respiratory distress syndrome (ARDS).

The investigators fill out a standard questionnaire for each participant. Data collected from the questionnaires through complete history taking, general examination, local examination, laboratory notes and ultrasound reports. Age, number of retrieved oocytes, number of follicles on day of hCG administration, assessment of mean ovarian diameter (MOD), estradiol level on the day of hCG administration recorded. Chemical pregnancy detected by the measurement of serum beta-hCG 14 days after the embryo transfer. The existence of clinical pregnancy confirmed using transvaginal ultrasound scan, which scheduled two weeks later to detect the gestational sac of pregnancy.

Patients followed up until the detection of fetal heart pulsation. Early OHSS (mild, moderate and severe) is defined as the onset of the syndrome during the first 9 days after HCG administration.

All of the patients were checked for any complaints or side effects of cabergoline. 


\section{Outcome measures:}

1- Primary outcome:
(a) OHSS
(b) Ovulation rate (monomolecular and multifollicular) development.
(c) Pregnancy rate

2- Secondary outcome:

Side effects and complications of therapy.

\section{Statistical methods}

The collected data were tabulated and analyzed using SPSS version 17. Categorical data were presented as number and percentages while quantitative data were expressed as mean and standard deviation. Chi square test (X2) and ANOVA (F) test were used as tests of significance.

The accepted level of significance in this work was stated at $0.05(\mathrm{P}<0.05$ was considered significant).

$\mathrm{P}$-value $>0.05$ insignificant $\mathrm{P}<0.05$ significant $\mathrm{P}<0.01$ highly significant

\section{RESULTS}

Table (1): Comparison of study population regarding the mean age:

\begin{tabular}{|c|c|c|c|c|}
\hline & \multicolumn{3}{|c|}{ Age/years } & \multicolumn{2}{c|}{ T-test } \\
\cline { 2 - 5 } & Range & Mean \pm SD & $t$ & P-value \\
\hline Group A & $19-34$ & $29.95 \pm 2.34$ & \multirow{2}{*}{1.465} & \multirow{2}{*}{0.146} \\
\hline Group B & $18-35$ & $29.15 \pm 3.07$ & & \\
\hline
\end{tabular}

There were no significant differences in the age in both groups. In the group A, the age was with a mean of $29.95 \pm 2.34$, while in the group B it was with a mean of $29.15 \pm 3.07,(p=0.146)$. Comparison between two groups showed no significant difference.

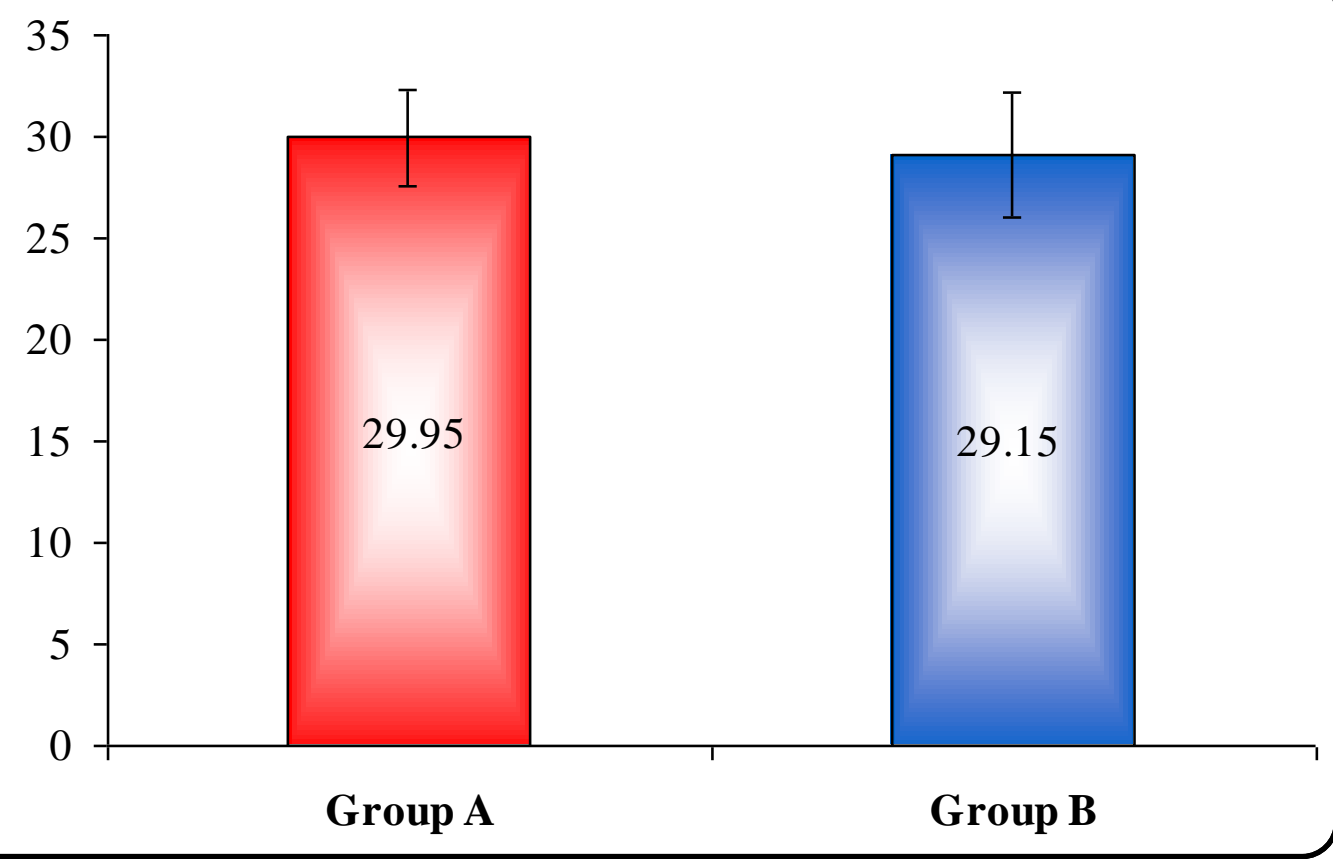

Figure (1): Comparison of study population regarding the mean age.

Table (2): Comparison of study groups as regards the BMI:

\begin{tabular}{|c|c|c|c|c|}
\hline & \multicolumn{2}{|c|}{ BMI } & \multicolumn{2}{|c|}{ T-test } \\
\hline & Range & Mean \pm SD & $\mathrm{t}$ & P-value \\
\hline Group A & $25-34$ & $26.46 \pm 3.82$ & 1050 & 0065 \\
\hline Group B & $27-35$ & $27.85 \pm 3.29$ & 1.950 & 0.005 \\
\hline
\end{tabular}

There were no significant differences in the Body mass index. In group A the BMI was with a mean of $26.46 \pm 3.82$, while in the group B it was with a mean of $27.85 \pm 3(\mathrm{p}=0.065)$. Comparison between all groups showed no significant difference. 


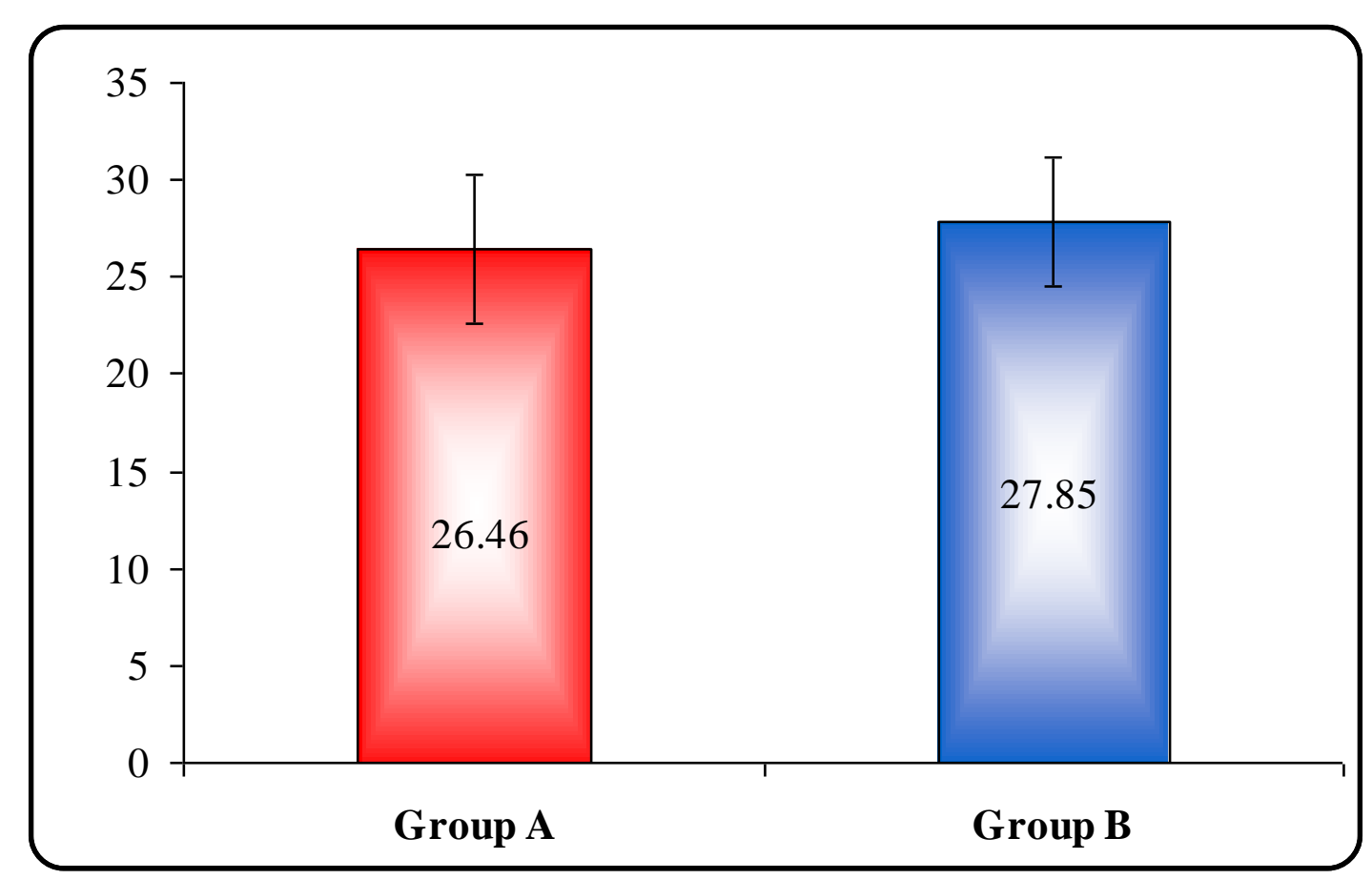

Figure (2): Comparison between all groups as regards the BMI.

Table (3): Comparison of study groups as regards the type of infertility:

\begin{tabular}{|c|c|c|c|c|c|c|c|}
\hline \multirow{2}{*}{\multicolumn{2}{|c|}{ type of infertility }} & \multicolumn{2}{|c|}{ Group A } & \multicolumn{2}{|c|}{ Group B } & \multicolumn{2}{|c|}{ Total } \\
\hline & & $\mathrm{N}$ & $\%$ & $\mathrm{~N}$ & $\%$ & $\mathrm{~N}$ & $\%$ \\
\hline \multicolumn{2}{|c|}{ 1ry infertility } & 34 & 68 & 35 & 70 & 69 & 69 \\
\hline \multicolumn{2}{|c|}{ 2ry infertility } & 16 & 32 & 15 & 30 & 31 & 31 \\
\hline \multicolumn{2}{|c|}{ Total } & 50 & 100 & 50 & 100 & 100 & 100 \\
\hline \multirow{2}{*}{ Chi-square } & $X^{2}$ & \multicolumn{6}{|c|}{0.047} \\
\hline & $\mathrm{P}$-value & \multicolumn{6}{|c|}{0.829} \\
\hline
\end{tabular}

Concerning the tow studied groups; primary infertility represented $68 \%$ and $70 \%$ in both groups respectively, while secondary infertility represented $32 \%$ and $30 \%$ in both groups respectively. Comparison between two groups showed no significant difference. 


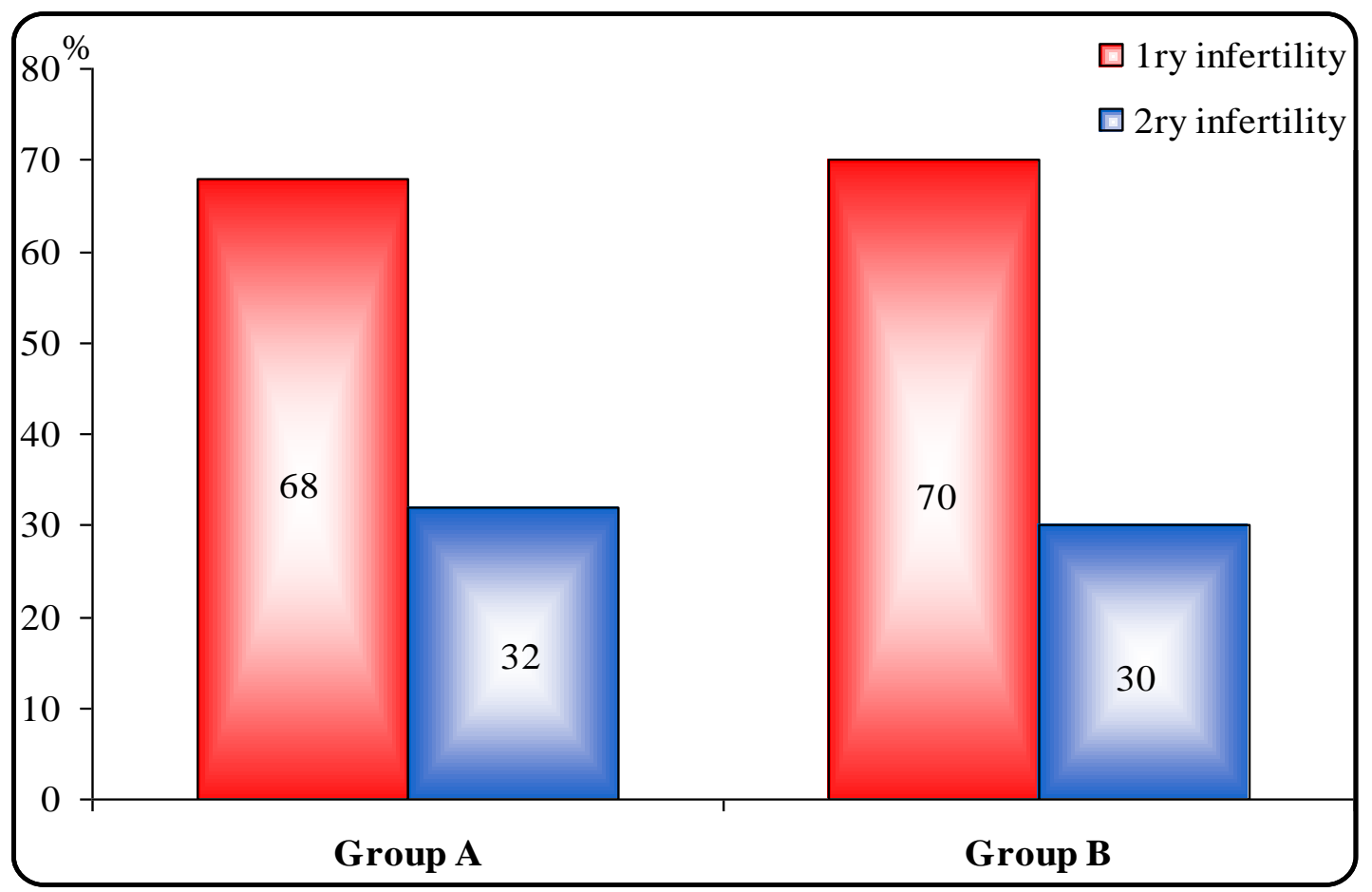

Figure (3): Comparison between two groups as regards the type of infertility.

Table (4): Comparison of study groups as regards FSH level:

\begin{tabular}{|c|c|r|c|c|}
\hline & \multicolumn{2}{|c|}{ FSH (Miu/ml) } & \multicolumn{2}{|c|}{ T-test } \\
\cline { 2 - 5 } & Range & Mean \pm SD & $t$ & P-value \\
\hline Group A & $4.23-7.12$ & $5.26 \pm 0.67$ & \multirow{2}{*}{1.713} & 0.089 \\
\hline Group B & $4.41-6.84$ & $5.02 \pm 0.73$ & & \\
\hline
\end{tabular}

The FSH in group A was with a mean of $5.26 \pm 0.67$, while in group B it was with a mean of $4.32 \pm$ 0.73 ( $\left.\mathrm{p}<0.001^{* *}\right)$. Comparison between two groups showed highly significant difference.

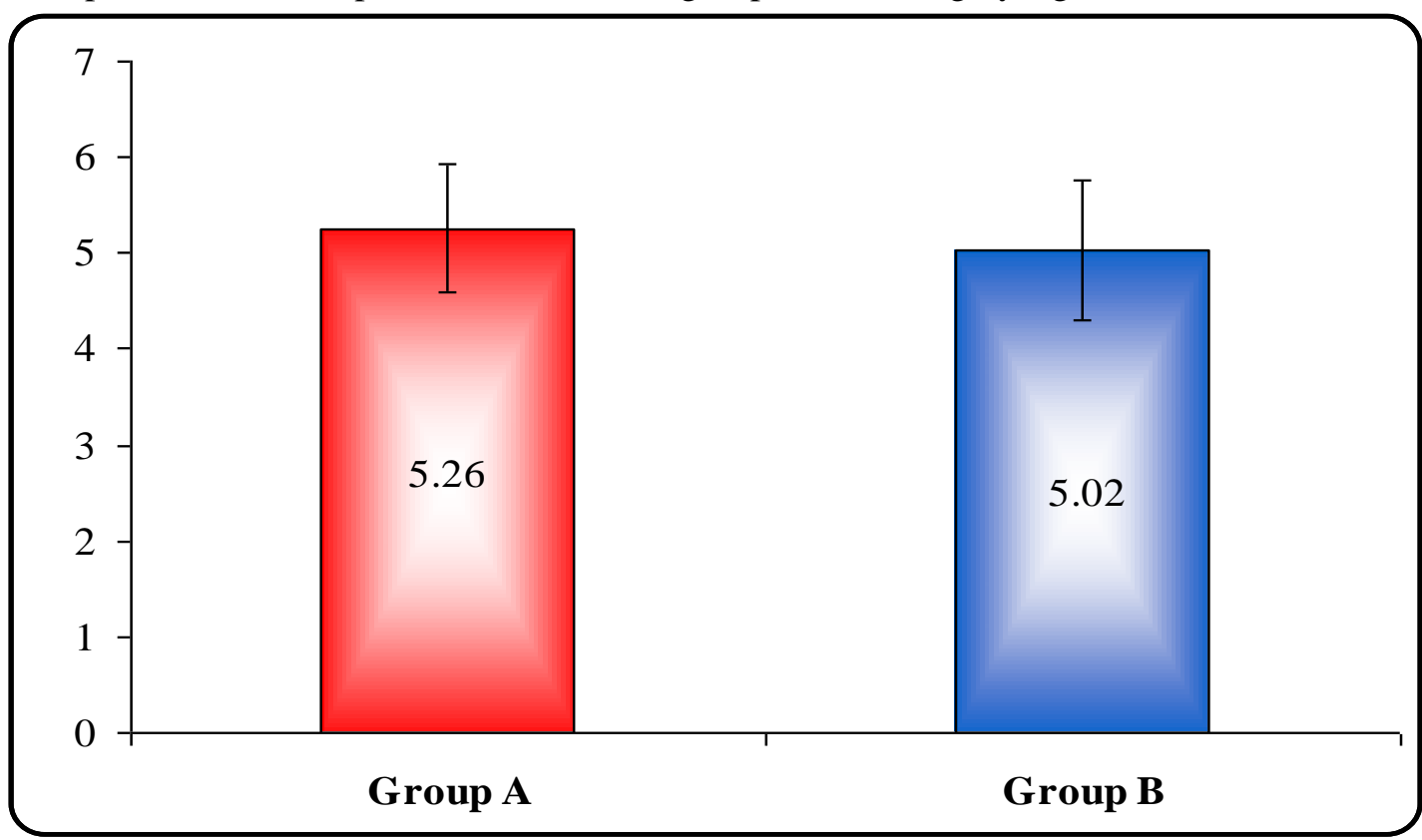

Figure (4): Comparison between all groups as regards the mean level of FSH. 
Table (5): Comparison of study groups as regards LH level:

\begin{tabular}{|c|c|c|c|c|}
\hline \multirow{2}{*}{} & \multicolumn{2}{|c|}{ LH (Miu/ml) } & \multicolumn{2}{|c|}{ T-test } \\
\cline { 2 - 5 } & Range & Mean \pm SD & $t$ & P-value \\
\hline Group A & $10.57-18.41$ & $14.21 \pm 1.34$ & \multirow{2}{*}{0.872} & 0.385 \\
\hline Group B & $9.62-15.37$ & $13.96 \pm 1.52$ & & \\
\hline
\end{tabular}

The LH in group A was with a mean of $14.21 \pm 1.34$, while in group B it was with a mean of $13.96 \pm$ 1.52. $(\mathrm{p}=0.385)$. Comparison between groups showed no significant difference.

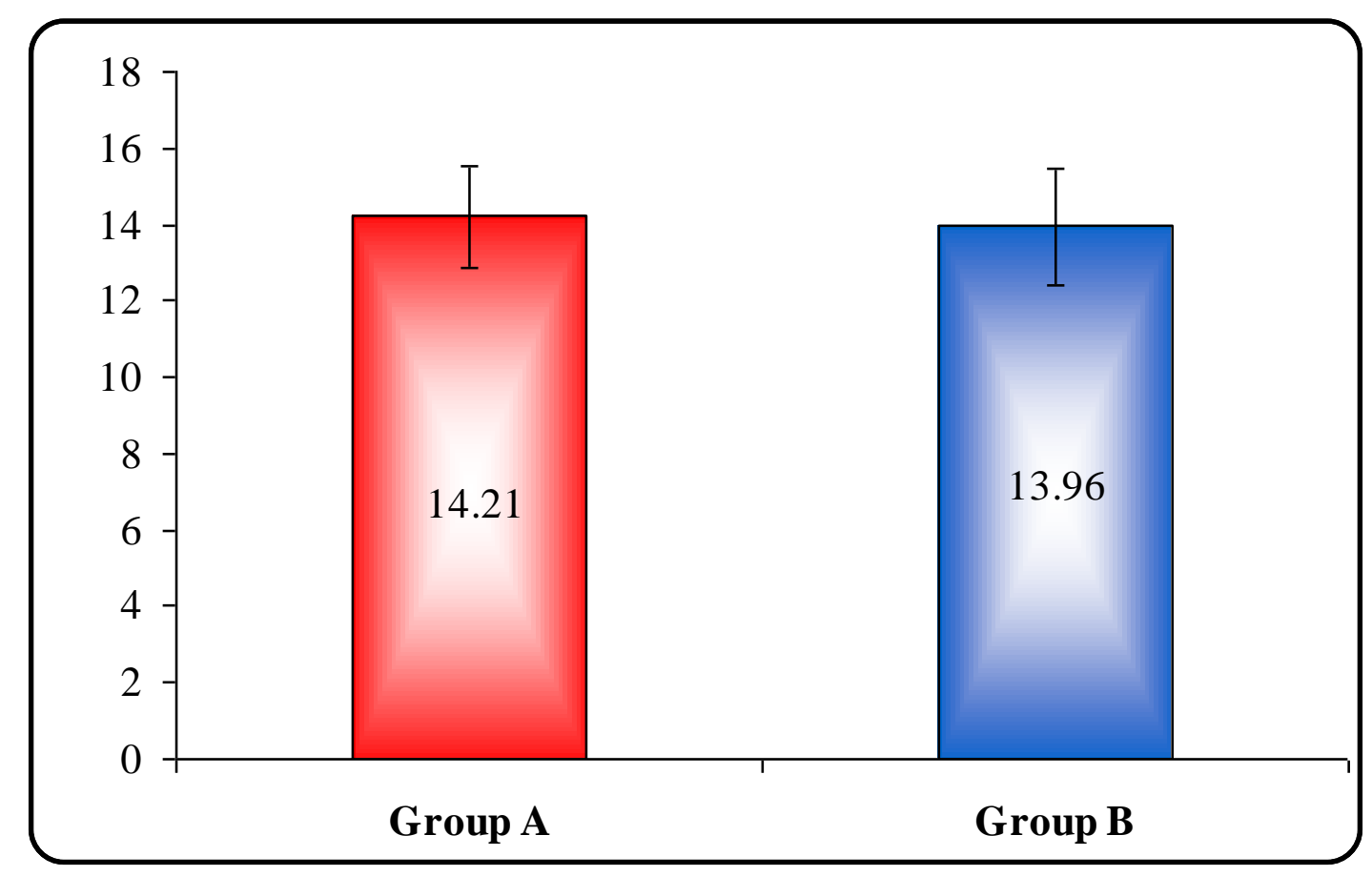

Figure (5): Comparison between two groups as regards the mean level of $\mathrm{LH}$

Table (6): Comparison of study two groups as regards the menstrual disorder:

\begin{tabular}{|l|c|c|c|c|c|c|}
\hline \multirow{2}{*}{ Menstrual disorder } & \multicolumn{2}{|c|}{ Group A } & \multicolumn{2}{c|}{ Group B } & \multicolumn{2}{c|}{ Chi-square } \\
\cline { 2 - 7 } & $\mathrm{N}$ & $\%$ & $\mathrm{~N}$ & $\%$ & $\mathrm{X}^{2}$ & P-value \\
\hline Oligomenorrhea & 30 & 60 & 31 & 62 & 0.042 & 0.838 \\
\hline Amenorrhea & 7 & 14 & 3 & 6 & 1.778 & 0.182 \\
\hline Normal Rhythm & 13 & 26 & 16 & 32 & 0.437 & 0.509 \\
\hline
\end{tabular}

In group A, (30) cases presented with oligomenorrhea (60\%) and only (7) cases had amenorrhea $(14 \%)$, and (13) had a normal rhythm (26\%), while in group B (31) cases had oligomenorrhea (62\%) only (3) case had amenorrhea (6\%) and(16) cases had normal rhythm (32\%). Comparison between two groups showed no significant difference. 


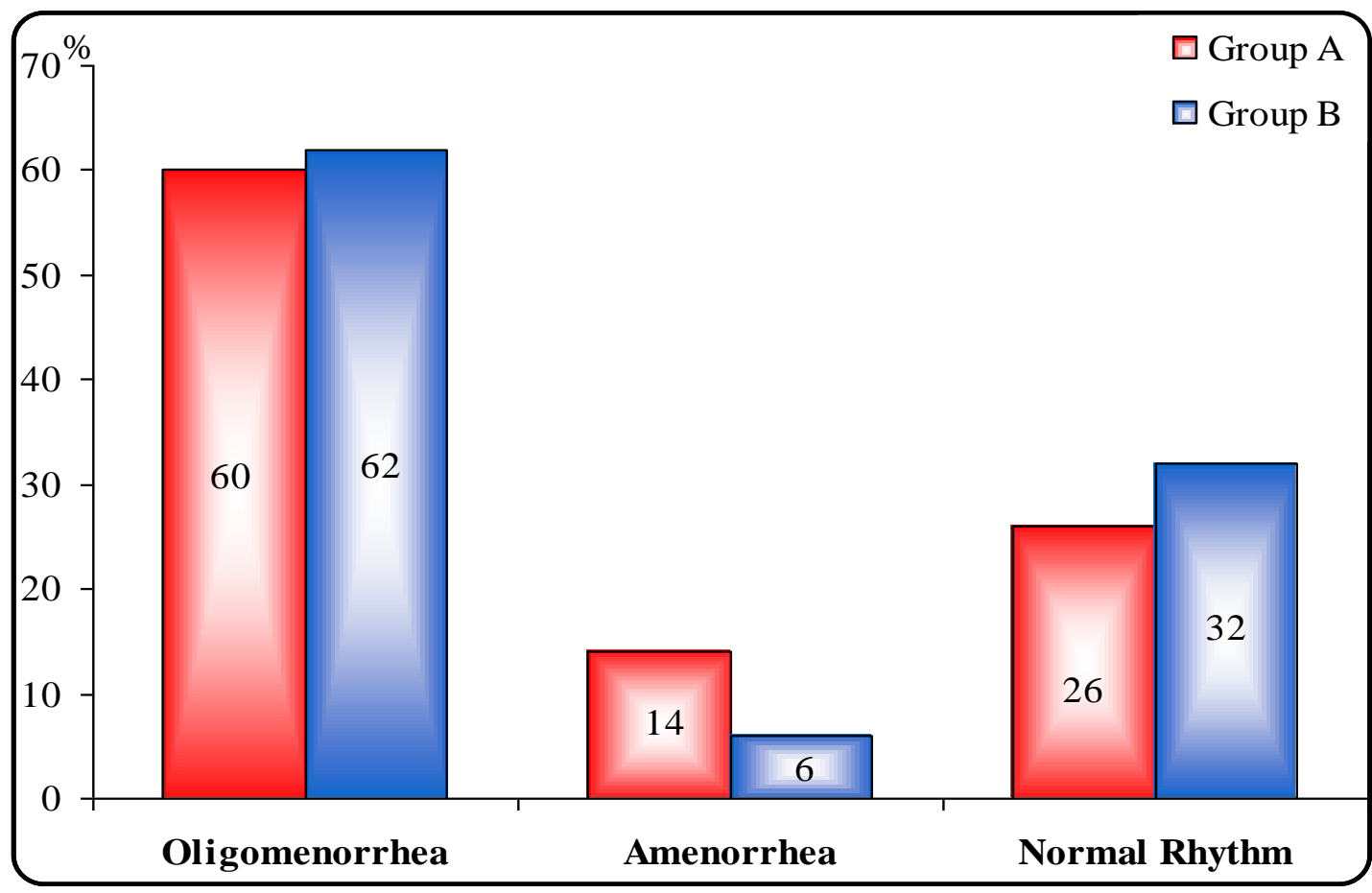

Figure (6): Comparison between two groups as regards the menstrual disorder.

Table (7): Comparison of study groups as regards acne rate:

\begin{tabular}{|c|c|c|c|c|c|c|c|}
\hline \multirow{2}{*}{\multicolumn{2}{|c|}{ Acne }} & \multicolumn{2}{|c|}{ Group A } & \multicolumn{2}{|c|}{ Group B } & \multicolumn{2}{|c|}{ Total } \\
\hline & & $\mathrm{N}$ & $\%$ & $\mathrm{~N}$ & $\%$ & $\mathrm{~N}$ & $\%$ \\
\hline \multicolumn{2}{|c|}{ Yes } & 18 & 36 & 20 & 40 & 38 & 38 \\
\hline \multicolumn{2}{|c|}{ No } & 32 & 64 & 30 & 60 & 62 & 62 \\
\hline \multicolumn{2}{|c|}{ Total } & 50 & 100 & 50 & 100 & 100 & 100 \\
\hline \multirow{2}{*}{ Chi-square } & $X^{2}$ & \multicolumn{6}{|c|}{0.170} \\
\hline & P-value & \multicolumn{6}{|c|}{0.680} \\
\hline
\end{tabular}

18 cases in group A 18 cases had acne (36\%) while 20 case in group B (40\%). Comparison between two groups showed no significant difference.

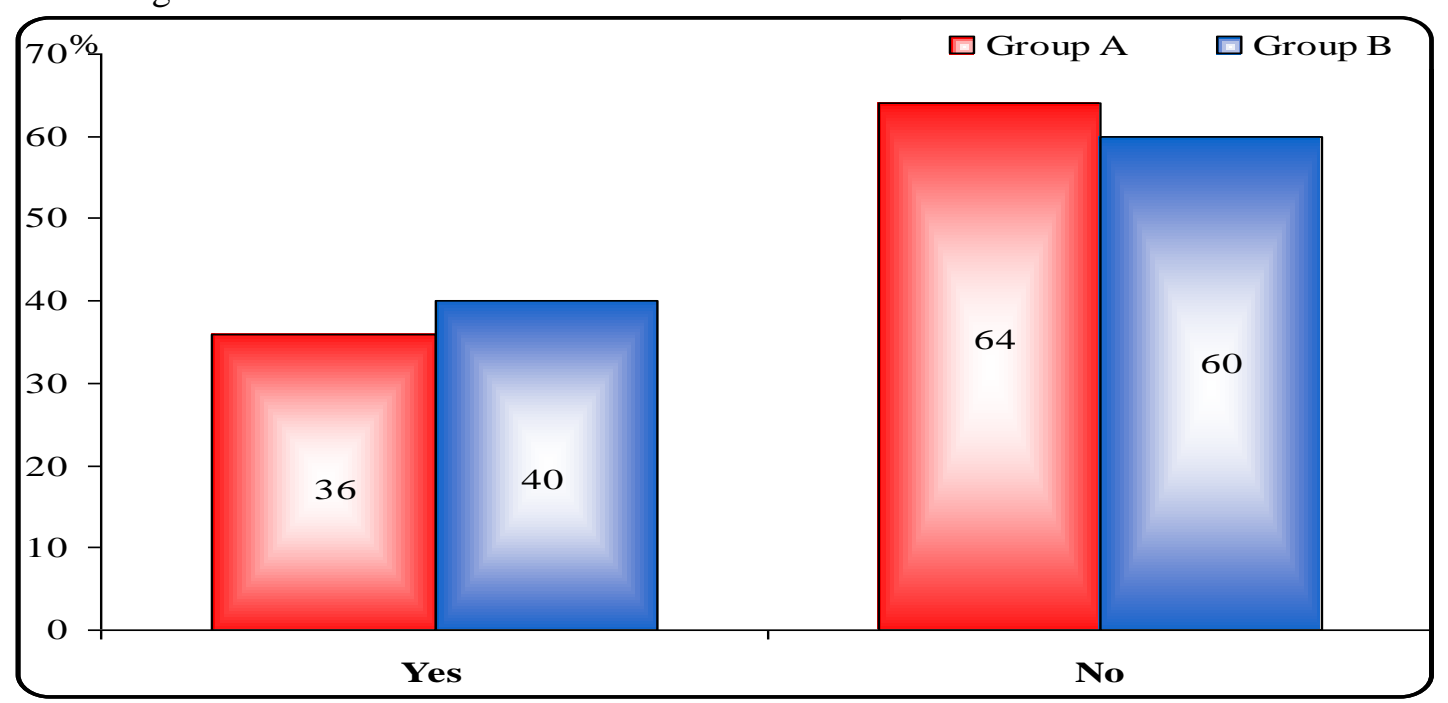

Figure (1): Comparison between two groups as regards the acne rate.

Table (8): Comparison of study groups as regards hirsutism rate: 
Ismaeil El-Garhy et al.

\begin{tabular}{|c|c|c|c|c|c|c|c|}
\hline \multirow{2}{*}{\multicolumn{2}{|c|}{ Hirsutism }} & \multicolumn{2}{|c|}{ Group A } & \multicolumn{2}{|c|}{ Group B } & \multicolumn{2}{|c|}{ Total } \\
\hline & & $\mathrm{N}$ & $\%$ & $\mathrm{~N}$ & $\%$ & $\mathrm{~N}$ & $\%$ \\
\hline \multicolumn{2}{|c|}{ Yes } & 20 & 40 & 22 & 44 & 42 & 42 \\
\hline \multicolumn{2}{|c|}{ No } & 30 & 60 & 28 & 56 & 58 & 58 \\
\hline \multicolumn{2}{|c|}{ Total } & 50 & 100 & 50 & 100 & 100 & 100 \\
\hline \multirow{2}{*}{ Chi-square } & $X^{2}$ & \multicolumn{6}{|c|}{0.164} \\
\hline & P-value & \multicolumn{6}{|c|}{0.685} \\
\hline
\end{tabular}

In group A, 20 cases presented with hirsutism (40\%), while in group B 22 case had hirsutism (44\%). Comparison between both groups showed no significant difference.

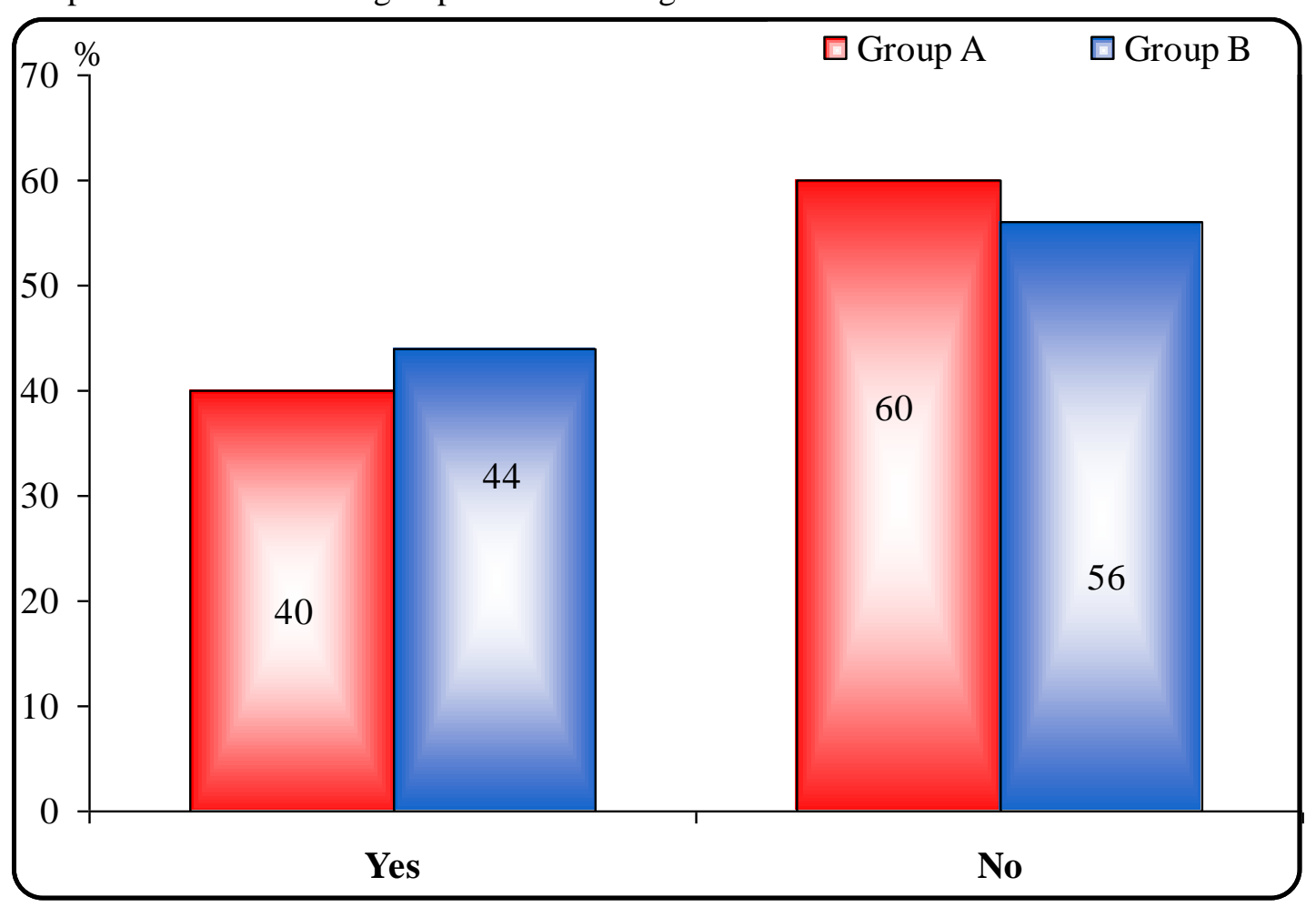

Figure (2): Comparison between two groups as regards hirsutism rate.

Table (9): $\quad$ Comparison of study groups as regards No. of follicles in both ovaries on day 0.

\begin{tabular}{|c|c|c|c|c|}
\hline \multirow{2}{*}{} & \multicolumn{2}{|c|}{ No. of follicles in both ovaries on day 0 } & \multicolumn{2}{|c|}{ T-test } \\
\cline { 2 - 5 } & Range & Mean \pm SD & $\mathrm{t}$ & P-value \\
\hline Group A & $21-30$ & $27.11 \pm 6.54$ & \multirow{2}{*}{1.287} & 0.201 \\
\hline Group B & $19-30$ & $28.54 \pm 4.35$ & & \\
\hline
\end{tabular}

The mean No. of follicles in both ovaries on day 0 in group A was $27.10 \pm 6.5$ in group B it was $28.5 \pm 8$. Comparison between both groups showed no significant difference. 


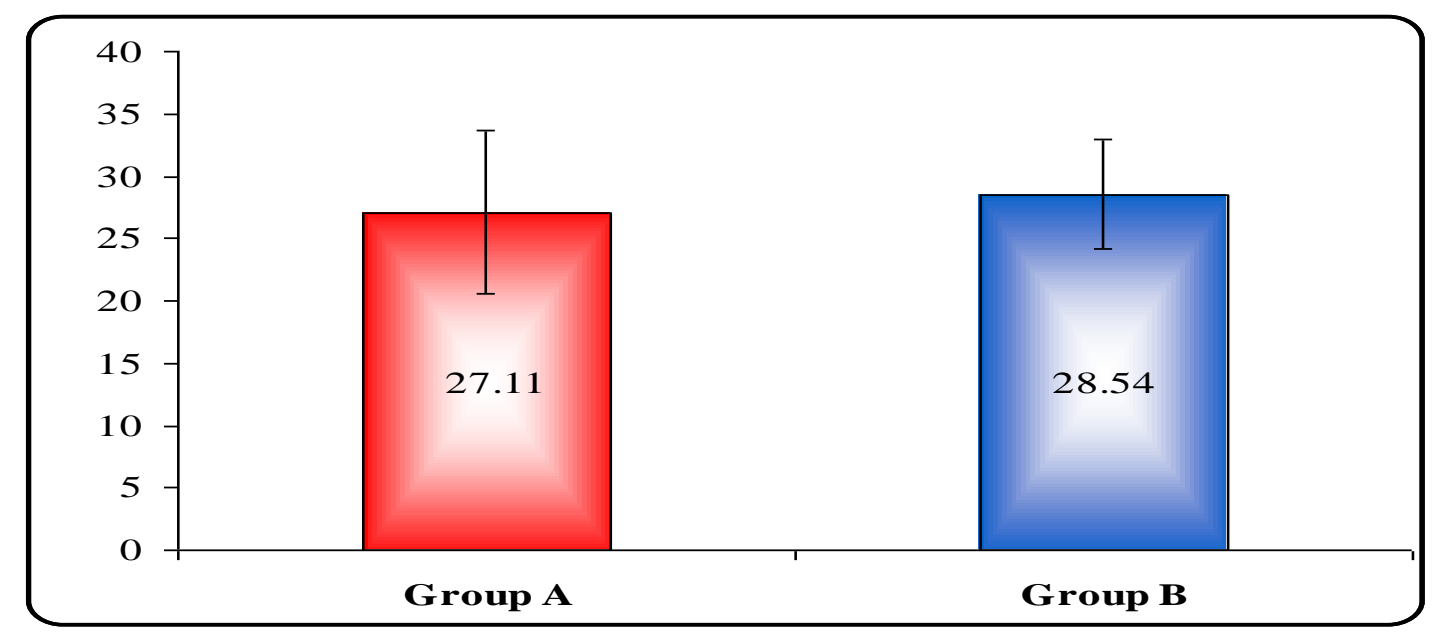

Figure (3): Comparison between two groups as regard No. of follicles in both ovaries on day 0 .

Table (1): Comparison of study groups as regards the mean diameter of follicle on day of hCG administration.

\begin{tabular}{|c|c|c|c|c|}
\hline \multirow{2}{*}{$\begin{array}{l}\text { Mean diameter of } \\
\text { follicles in } \mathrm{mm}\end{array}$} & Group A & Group B & \multicolumn{2}{|c|}{ T-test } \\
\hline & Mean \pm SD & Mean \pm SD & $\mathrm{t}$ & P-value \\
\hline $10-14 \mathrm{~mm}$ & $9.3 \pm 3.5$ & $9.4 \pm 2.9$ & 0.081 & 0.936 \\
\hline $15-17 \mathrm{~mm}$ & $4.9 \pm 1.4$ & $5.6 \pm 1.1$ & 1.263 & 0.209 \\
\hline$>18 \mathrm{~mm}$ & $5.7 \pm 1.7$ & $5.9 \pm 1.3$ & 0.332 & 0.741 \\
\hline
\end{tabular}

The diameter of follicles in group A from(4-10mm) was mean 10, from (11-20mm) was mean 39 and from $(20-30 \mathrm{~mm})$ was mean 8. while the mean diameter of follicle in group B from $(4-10 \mathrm{~mm})$ was mean 13 , from $(11-20 \mathrm{~mm})$ was mean 37 and from $(20-30 \mathrm{~mm})$ was mean 10 ( $\left.\mathrm{p}<0.001^{* *}\right)$. Comparison between both groups showed highly significant difference.

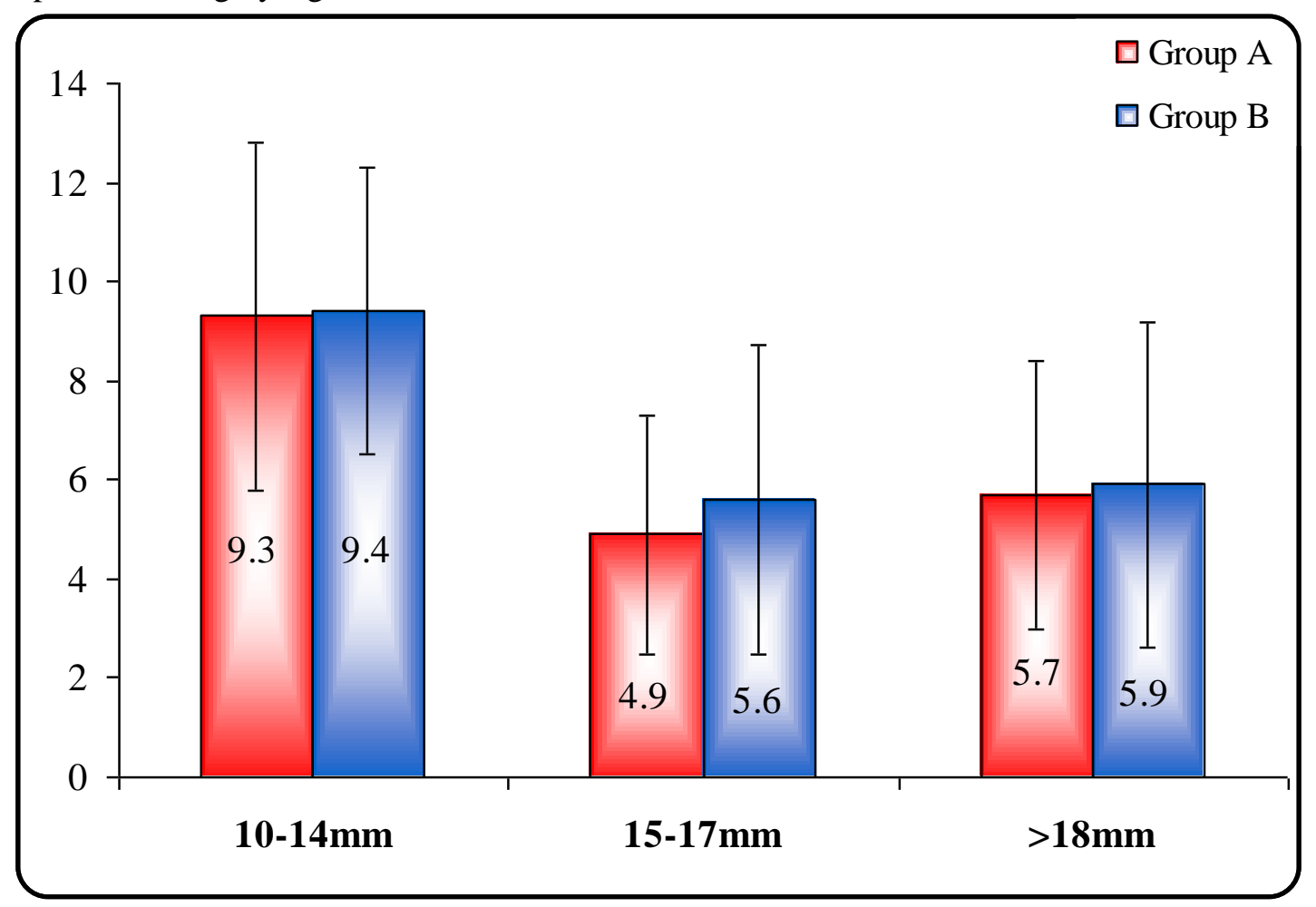

Figure (4): Comparison between two groups as regards the mean diameter of follicles on day of hCG administration. 
Ismaeil El-Garhy et al.

Table (2): $\quad$ Comparison of study groups as regards the mean number of follicles retrieved.

\begin{tabular}{|c|c|c|c|c|}
\hline & \multicolumn{2}{|c|}{ Mean mumber of follicles retrived } & \multicolumn{2}{|c|}{ T-test } \\
\cline { 2 - 5 } & Range & Mean \pm SD & $\mathrm{t}$ & P-value \\
\hline Group A & $16-25$ & $18.3 \pm 5.1$ & \multirow{2}{*}{4.295} & $<0.001^{* *}$ \\
\hline Group B & $12-20$ & $14.24 \pm 4.32$ & & \\
\hline
\end{tabular}

In group $\mathrm{A}$, the mean number of follicle retrieved was 18.3 \pm 5.1 , while in group $\mathrm{B}$ the number was 14.24 4.32. Comparison between all groups showed highly significant difference.

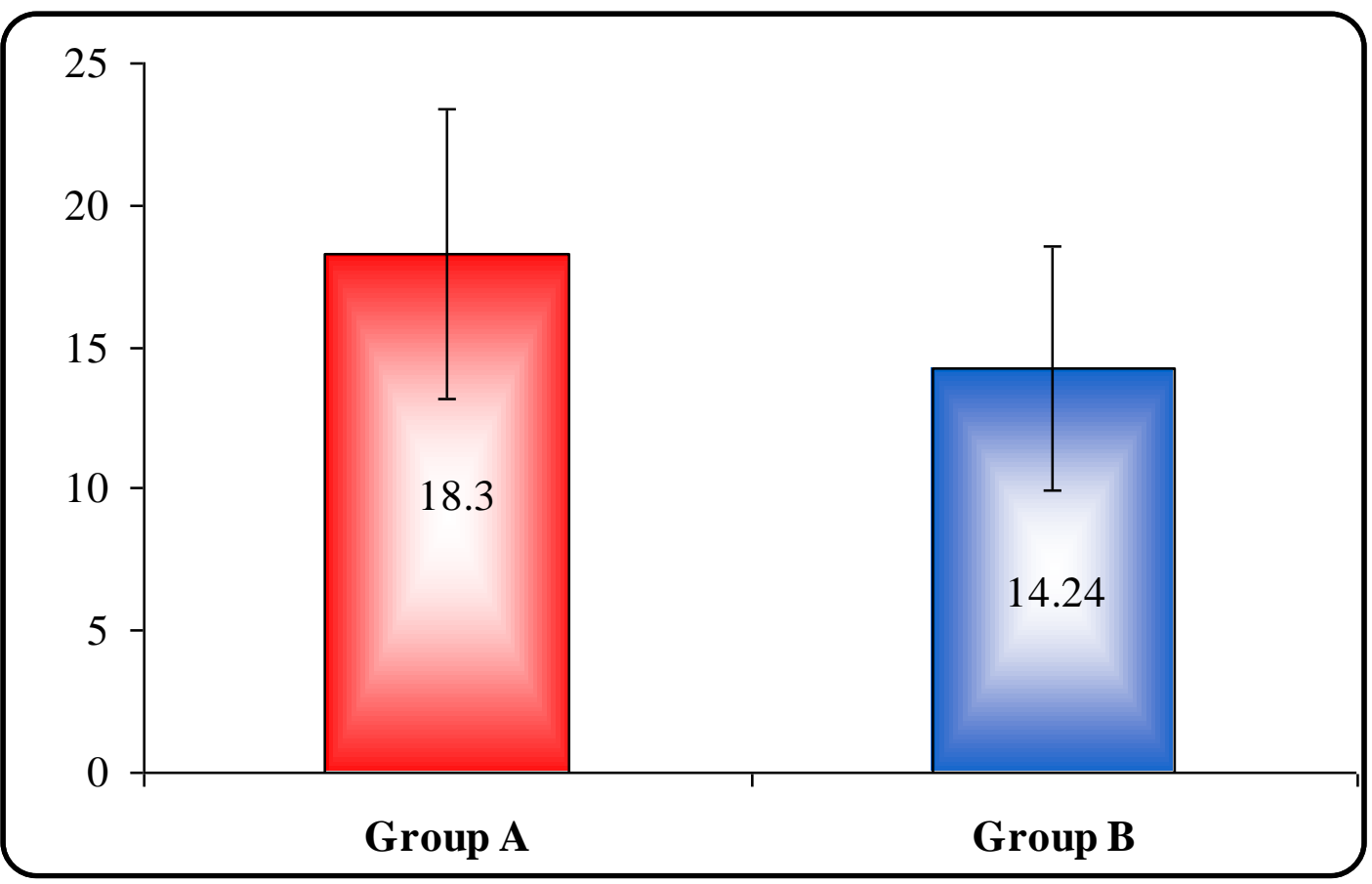

Figure (5): Comparison between both groups as regards the mean number of follicles retrieved.

Table (12): Comparison of study groups as regards E2 level on day of hCG administration:

\begin{tabular}{|c|c|c|c|c|}
\hline \multirow{2}{*}{} & \multicolumn{2}{|c|}{ E2 (Pg/ml) } & \multicolumn{2}{|c|}{ T-test } \\
\cline { 2 - 5 } & Range & Mean \pm SD & $t$ & P-value \\
\hline Group A & $2342.6-4287.8$ & $3477.51 \pm 402.15$ & \multirow{2}{*}{6.504} & $<0.001^{* *}$ \\
\hline Group B & $2257.3-4361.3$ & $2885.43 \pm 502.64$ & & \\
\hline
\end{tabular}

The E2 level in group A was with a mean of 3477.51, while in group B it was with a mean of $2885.43(\mathrm{p}=<0.001)$. Comparison between both groups showed highly statistically significant difference. 


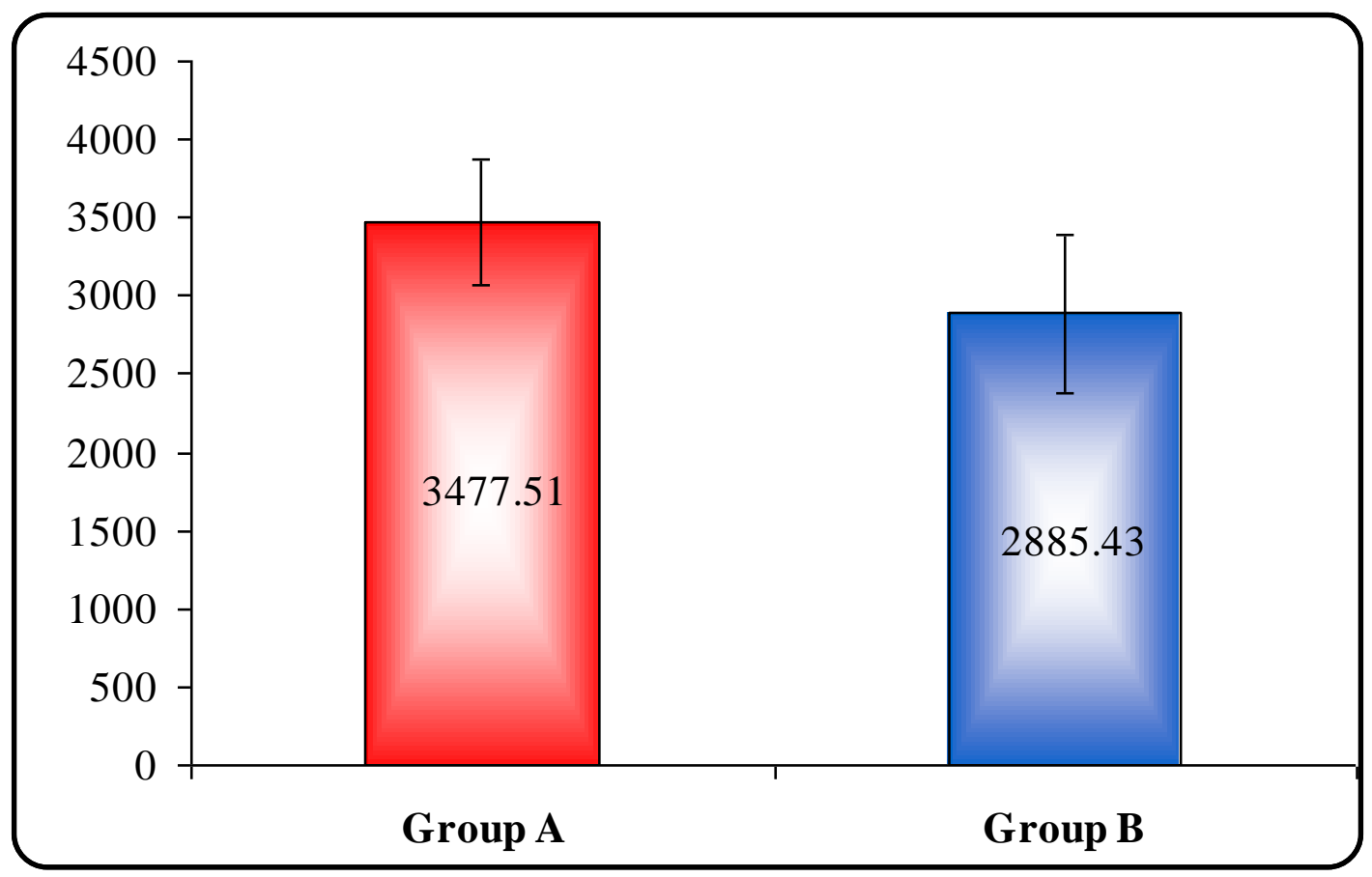

Figure (12): Comparison between two groups as regards the level of E2 day of hCG administration .

Table (13): Comparison of study groups as regards pregnancy rate:

\begin{tabular}{|c|c|c|c|c|c|c|}
\hline \multirow{2}{*}{ Pregnancy rate } & \multicolumn{2}{|c|}{ Group A } & \multicolumn{2}{|c|}{ Group B } & \multicolumn{2}{|c|}{ Chi-square } \\
\hline & $\mathrm{N}$ & $\%$ & $\mathrm{~N}$ & $\%$ & $\mathrm{X}^{2}$ & P-value \\
\hline BHCG +ve & $24 / 50$ & 48 & $12 / 50$ & 24 & \multirow{2}{*}{6.250} & \multirow{2}{*}{$0.012 *$} \\
\hline -ve & $26 / 50$ & 52 & $38 / 50$ & 76 & & \\
\hline Clinical pregnancy & $18 / 24$ & 75 & $10 / 12$ & 83.3 & \multirow{2}{*}{0.321} & \multirow{2}{*}{0.571} \\
\hline Miscarriage & $6 / 24$ & 25 & $2 / 12$ & 16.7 & & \\
\hline Total & 50 & 100 & 50 & 100 & 100 & 100 \\
\hline
\end{tabular}

Only 24 cases in group A got pregnant (48\%) while 12 cases in group B conceived $(24 \%)$. Comparison between two groups showed significant difference.

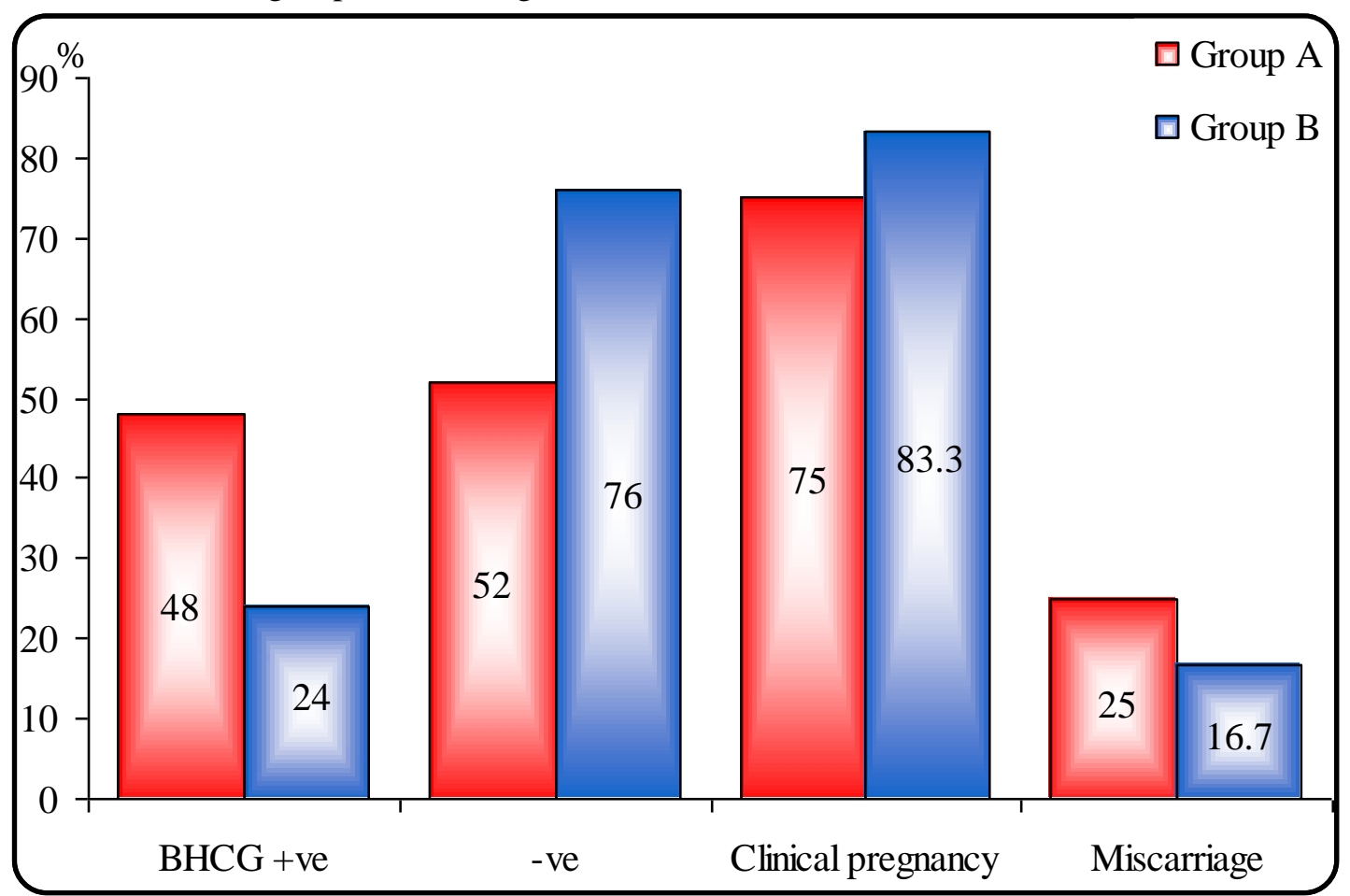

Figure (13): Comparison between both groups as regard the pregnancy rate. 
Table (14): Comparison of study groups as regards the development of mild OHSS.

\begin{tabular}{|c|c|c|c|c|c|c|}
\hline \multirow{2}{*}{ OHSS } & \multicolumn{2}{|c|}{ Group A } & \multicolumn{2}{c|}{ Group B } & \multicolumn{2}{c|}{ Total } \\
\cline { 2 - 7 } & $\mathrm{N}$ & $\%$ & $\mathrm{~N}$ & $\%$ & $\mathrm{~N}$ & $\%$ \\
\hline No & 34 & 68 & 19 & 38 & 53 & 34 \\
\hline Mild & 13 & 26 & 19 & 38 & 32 & 13 \\
\hline Moderate & 2 & 4 & 10 & 20 & 12 & 2 \\
\hline Severe & 1 & 2 & 2 & 4 & 3 & 1 \\
\hline Total & 50 & 100 & 50 & 100 & 100 & 50 \\
\hline \multirow{2}{*}{ Chi-square } & $\mathrm{X}^{2}$ & \multicolumn{6}{|c|}{11.037} \\
\cline { 2 - 7 } & P-value & \multicolumn{7}{|c|}{$012^{*}$} \\
\hline
\end{tabular}

Only 13 cases in group A developed mild OHSS (26\%) moderate 2(4\%) and severe 1(2\%) while 20 cases in group B (40\%) moderate 12(24\%) and severe $2(4 \%)$ Comparison between all groups showed highly significant difference.

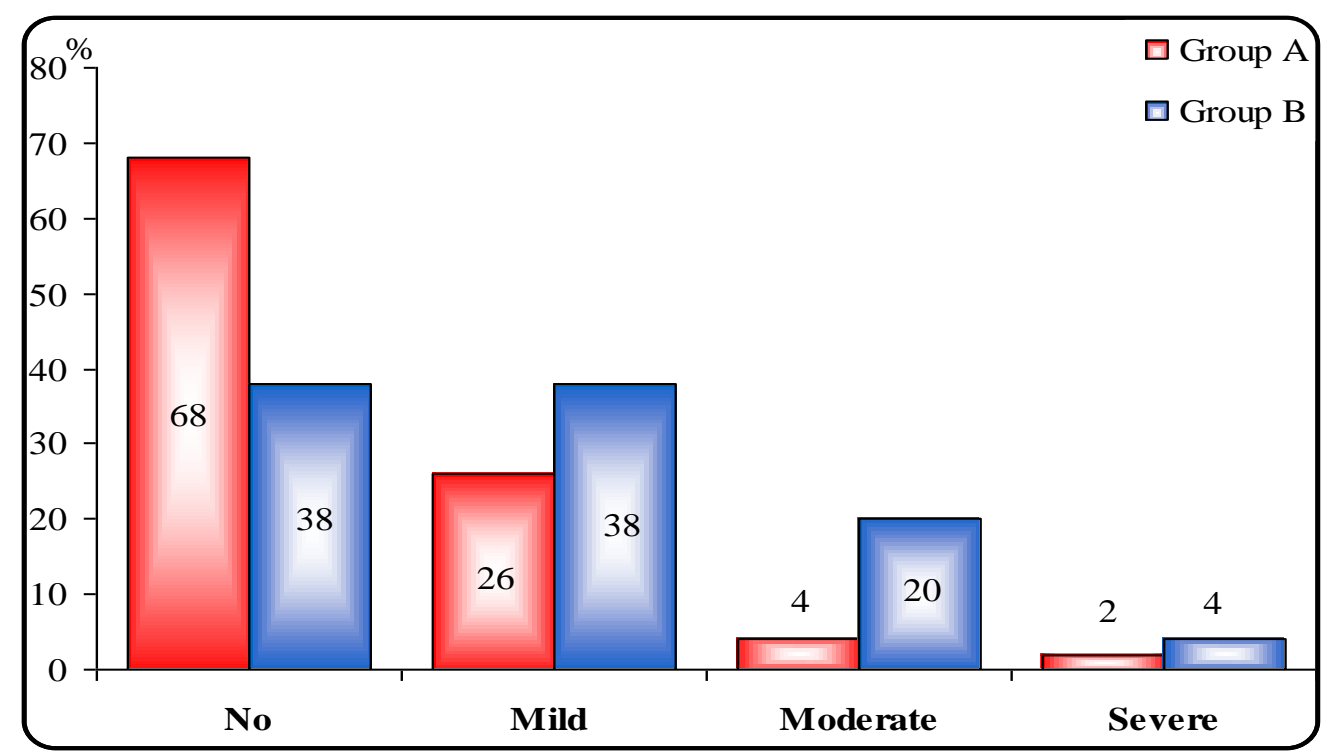

Figure (14): Comparison between all groups as regards the development of mild OHSS.

Table (15): Comparison of study groups as regards No of frozen embryos.

\begin{tabular}{|c|c|r|c|c|}
\hline & \multicolumn{3}{|c|}{ No of frozen embryos } & \multicolumn{2}{c|}{ T-test } \\
\cline { 2 - 4 } & Range & Mean \pm SD & \multirow{2}{*}{1.439} & \multirow{2}{*}{0.153} \\
\hline Group A & $5-11$ & $7.52 \pm 3.25$ & \\
\hline Group B & $5-9$ & $6.74 \pm 2.03$ & & \\
\hline
\end{tabular}

The mean No. of frozen embryos in group A was $9.5 \pm 4.8$ in group B it was 3.74 \pm 1.03 . Comparison between both groups showed highly significant difference.

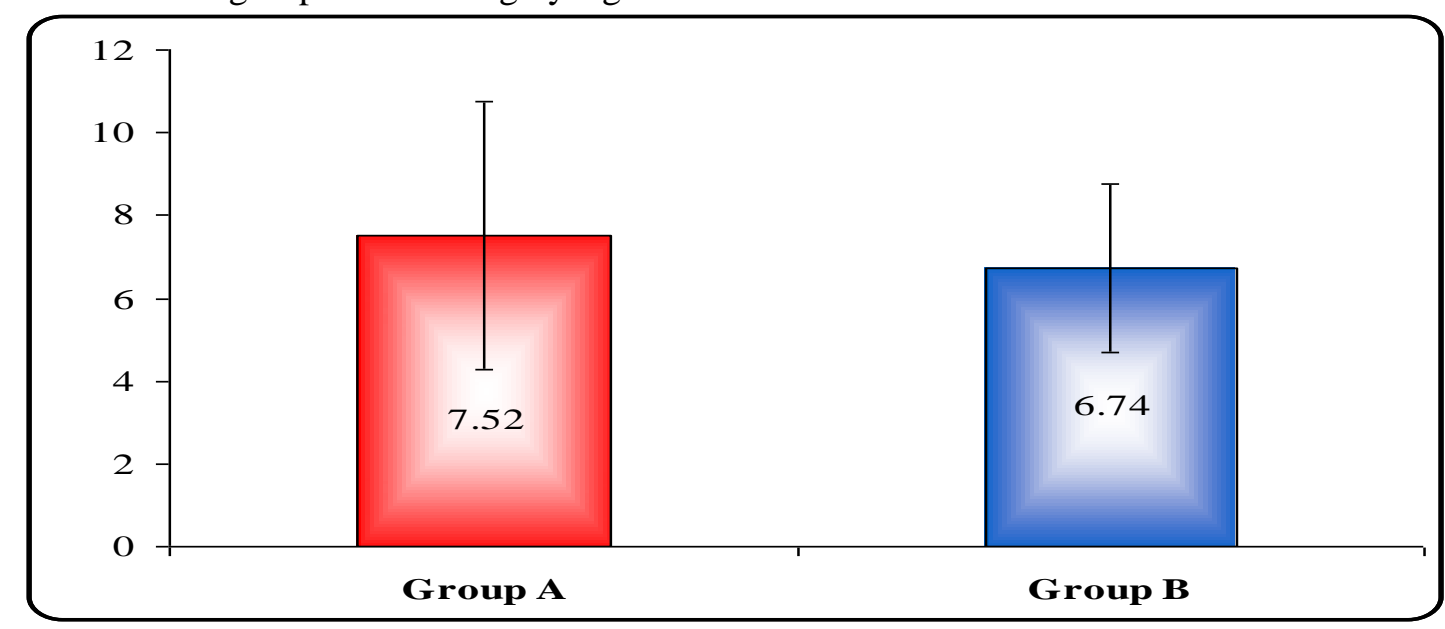

Figure (15): Comparison between two groups as No of frozen embryos. 
Table (16): Comparison of study groups as regards No. of recombinant hFSH (75 IU/ampoule).

\begin{tabular}{|c|c|c|c|c|}
\hline & \multicolumn{2}{|c|}{ No. of recombinant hFSH (75 IU/ampoule) } & \multicolumn{2}{c|}{ T-test } \\
\cline { 2 - 4 } & Range & Mean \pm SD & $t$ & P-value \\
\hline Group A & $13-19$ & $17.52 \pm 2.54$ & \multirow{2}{*}{4.456} & \multirow{2}{*}{$<0.001^{* *}$} \\
\hline Group B & $12-16$ & $14.81 \pm 3.47$ & & \\
\hline
\end{tabular}

The mean No. of recombinant hFSH (75 IU/ampoule) in group A was $17.5 \pm 2.5$ in group B it was $14.81 \pm 3.4$. Comparison between both groups showed highly significant difference.

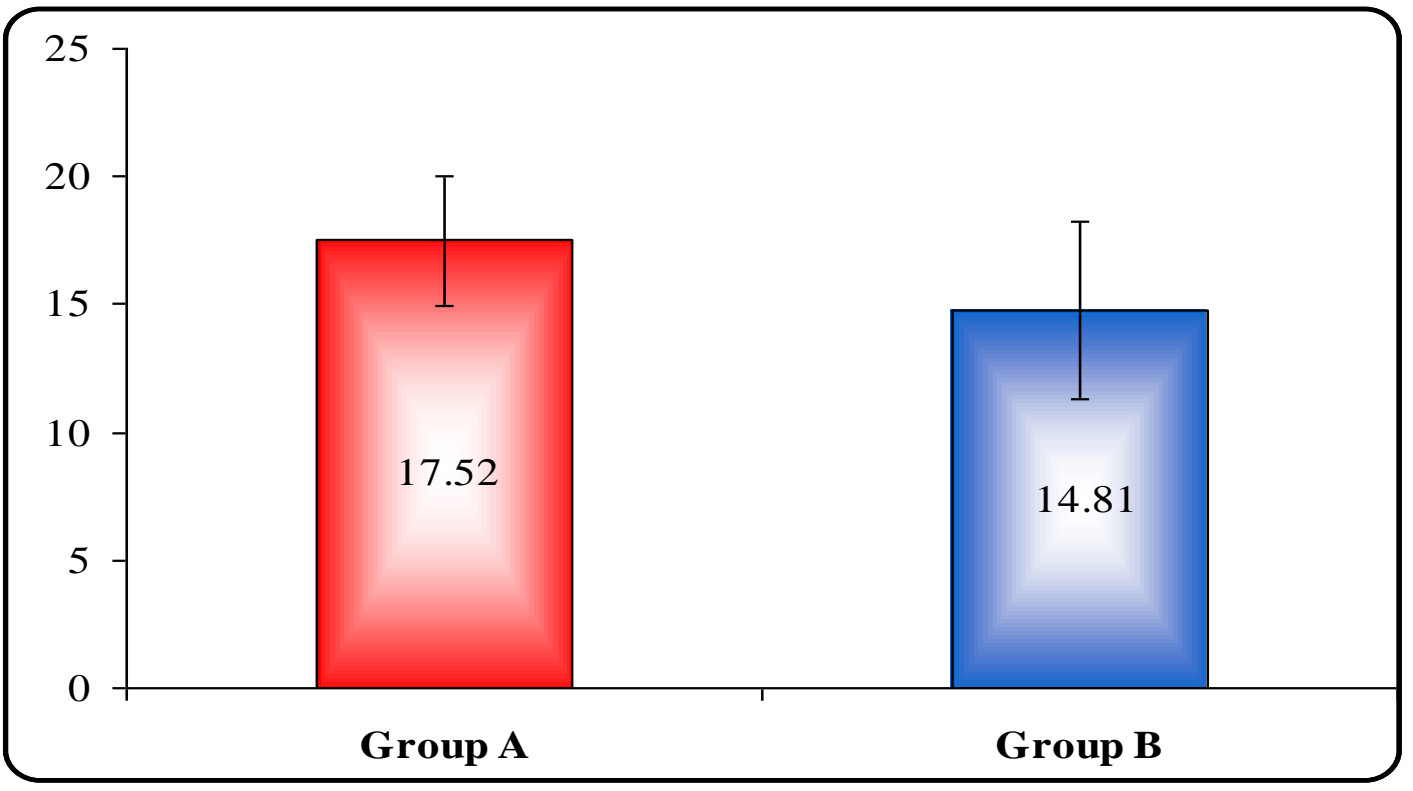

Figure (16): Comparison between two groups as No. of recombinant hFSH (75 IU/ampoule).

Table (17): Comparison of study groups as regards Duration of rFSH administration (days).

\begin{tabular}{|c|c|r|c|c|}
\hline & \multicolumn{2}{|c|}{ Duration of rFSH administration (days) } & \multicolumn{2}{c|}{ T-test } \\
\cline { 2 - 4 } & \multicolumn{2}{|c|}{ Range } & Mean \pm SD & \multirow{2}{*}{ P-value } \\
\hline Group A & $7-11$ & $9.6 \pm 2.2$ & \multirow{2}{*}{0.139} \\
\hline Group B & $7-10$ & $9.05 \pm 1.4$ & & \\
\hline
\end{tabular}

The mean duration of rFSH administration (days) in group A was 9.6 2.2 in group B it was 9. $05 \pm$ 1.4. Comparison between both groups showed no significant difference.

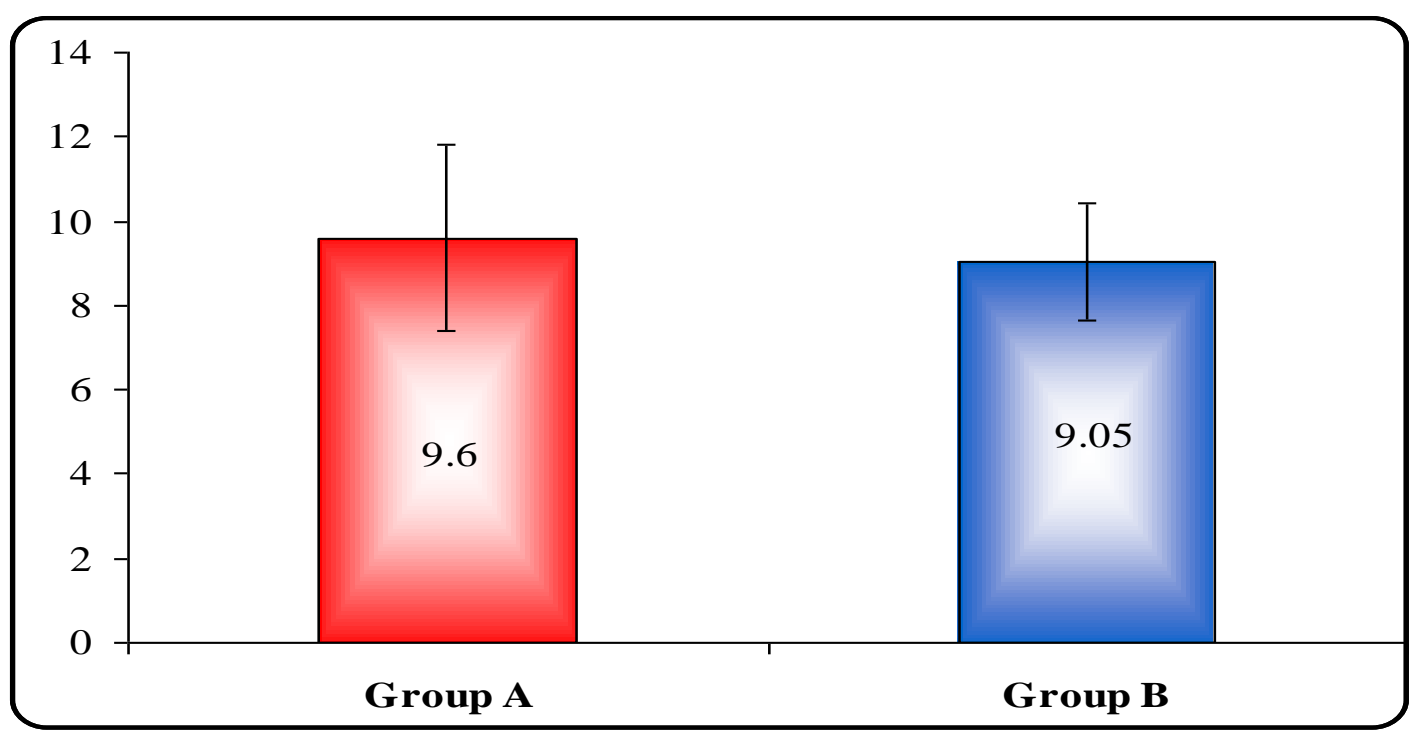

Figure (17): Comparison between two groups as regard Duration of rFSH administration (days) 
Ismaeil El-Garhy et al.

Table (18): Comparison of study groups as regards No. of MII oocytes.

\begin{tabular}{|c|c|c|c|c|}
\hline \multirow{2}{*}{} & \multicolumn{3}{|c|}{ No. of MII oocytes } & \multicolumn{2}{|c|}{ T-test } \\
\cline { 2 - 5 } & Range & Mean \pm SD & $t$ & P-value \\
\hline Group A & $16-24$ & $19.62 \pm 4.85$ & \multirow{2}{*}{5.964} & $<0.001^{* *}$ \\
\hline Group B & $7-16$ & $11.27 \pm 8.63$ & & \\
\hline
\end{tabular}

The mean No. of MII oocytes in group A was 19.62 \pm 4.85in group B it was 11.27 \pm 8.63 Comparison between both groups showed highly significant difference.

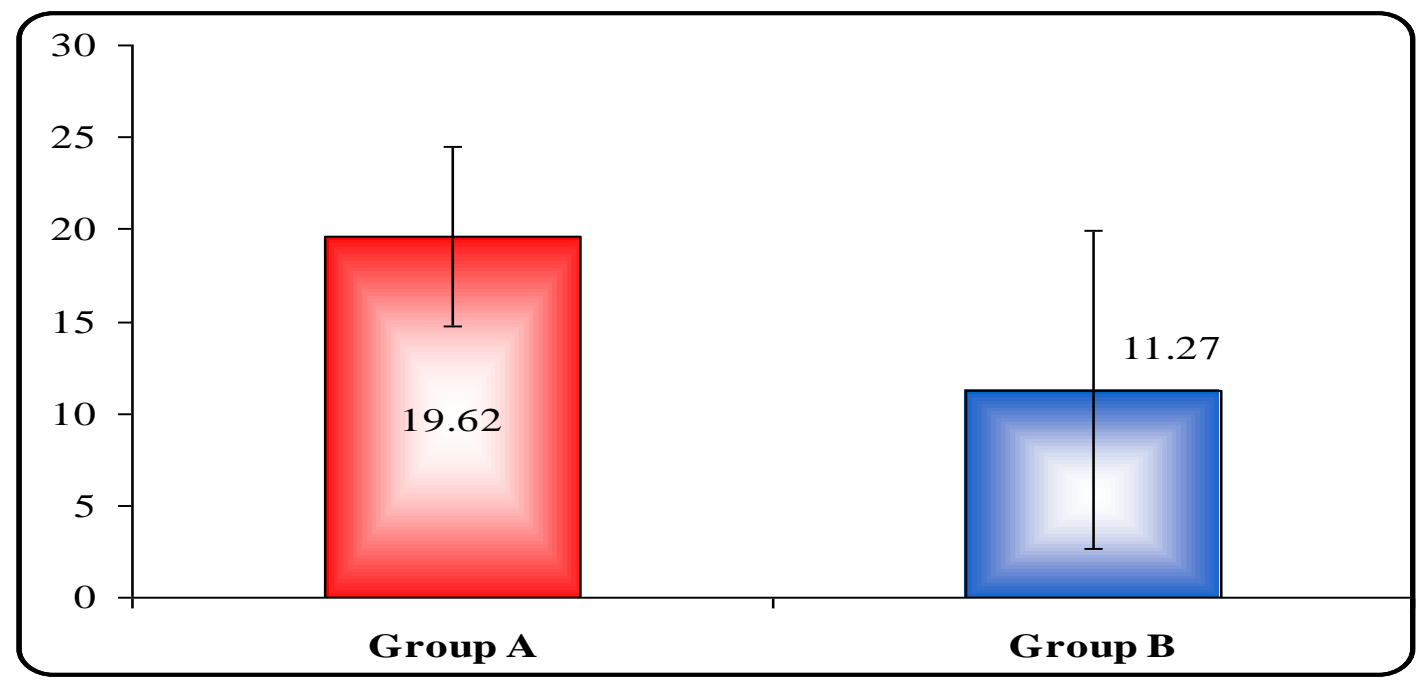

Figure (18): Comparison between two groups as regard No. of MII oocytes.

Table (19): Comparison of study groups as regards days of coasting

\begin{tabular}{|c|c|c|c|c|}
\hline \multirow{2}{*}{} & \multicolumn{4}{|c|}{ Duration of coasting (days) } \\
\cline { 2 - 5 } & \multicolumn{2}{|c|}{ Group A } & \multicolumn{2}{c|}{ Group B } \\
\cline { 2 - 5 } & $\mathrm{N}$ & $\%$ & $\mathrm{~N}$ & $\%$ \\
\hline 1 day & 0 & 0.0 & 10 & 20 \\
\hline 2 days & 0 & 0.0 & 28 & 56 \\
\hline 3 days & 0 & 0.0 & 8 & 16 \\
\hline 4 days & 0 & 0.0 & 4 & 8 \\
\hline $\begin{array}{c}\text { Mean } \pm \text { SD } \\
\text { Range }\end{array}$ & & & \multicolumn{3}{|c|}{$\begin{array}{c}\mathbf{1 . 9 \pm 0 . 8} \\
(\mathbf{1 - 4})\end{array}$} \\
\hline
\end{tabular}

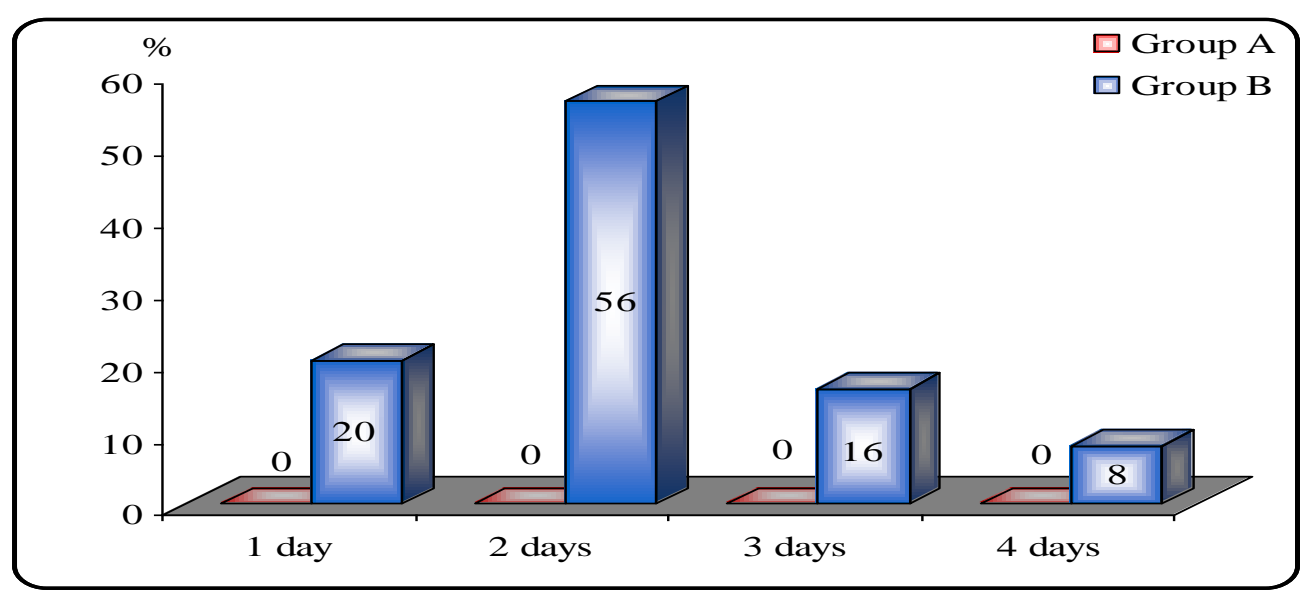

Figure (19): Comparison between two groups as regard days of coasting 


\section{DISCUSSION}

Various methods have been recommended to help in decreasing the incidence of ovarian hyperstimulation in high-risk patients with coasting being the most popular one ${ }^{(6)}$; although opinions vary about its effect on ART outcome. A previous study ${ }^{(10)}$ showed that VEGF plays a fundamental role in the pathogenesis of OHSS by acting on the microvascular system, increasing vascular permeability and third space fluid shift. In addition, dopamine agonists produce antiVEGF action which can help decrease VEGF receptor phosphorylation through D2 receptors. Thus, it may be possible to prevent OHSS by using dopamine, especially D2 dopamine agonists.

This prospective study was performed to assess and compare coasting with low-dose cabergoline administration in prevention of OHSS in high-risk patients. In a big cohort study performed by Mansour et al. ${ }^{(11)}$ to determine the exact criteria for coasting, this protocol was regarded to be effective in reducing the incidence of OHSS to 16 out of 1223 (1.3\%) in high risk patients. None of our patients experienced severe OHSS this may be due to low-dose gonadotropin ovarian stimulation, and by selecting a 3000 $\mathrm{pg} / \mathrm{mL}$ cut-off serum estradiol level for intervention. However, twelve patients in group B experienced moderate OHSS, while only tow patients in group A were experienced such complication. The time of ceasing gonadotropin therapy and starting coasting is of much importance ${ }^{(\mathbf{1 2})}$.

A study performed by Delvign and Rozenberg (13) showed that the duration of coasting has no effect on the outcome of in vitro fertilization (IVF). Also, it was seen that the rate of serum E2 fall during coasting is not important (14). However a study performed by Mansour $\boldsymbol{e t}$ al. ${ }^{(11)}$ showed that ICSI outcome is related to the number of days of coasting. When coasting is continued for more than three days the number of retrieved oocytes, implantation and clinical pregnancy rate will clearly fall and the frequency of adverse effects rises in direct proportion to the duration of coasting. Although the mean duration of coasting was short in our study $1.9 \pm 0.8^{\left({ }^{(15)} \text {, }\right.}$ but serum estradiol levels showed significant change on the day of hCG administration and only two patients required more than three days of coasting with no pregnancy.

The study performed by Egbase $\boldsymbol{e t}$ al. (16) which compared coasting and early unilateral follicular aspiration (EUFA) showed that the total number of retrieved oocytes was lower in the coasting group, which was attributed to atresia of smaller follicles. In the present study the total number and metaphase II oocytes were clearly more in patients in group A than group B. In addition, the fertilization rate was markedly lower in group B and total number of high quality embryos was more in group A. Although this difference was not statistically significant, but clinically it is of importance because this finding is contrary to previous studies which show that coasting does not affect fertilization and embryo quality ${ }^{(16)}$.

A previous study (17) showed that coasting and the associated decrease in estradiol level does not affect clinical pregnancy rate. Clinical pregnancy rate in our study was clearly higher in group A (48\%) than group B (24\%).

The mechanism of coasting has recently been described by García-Velasco et al. ${ }^{(18)}$ who showed that coasting causes apoptosis in moderate or small sized follicles. They also showed that coasting decreases VEGF protein secretion and gene expression in granulosa cells, especially in smaller follicles.

However, Ajonuma et al. ${ }^{\left({ }^{(19)}\right.}$ believed that this effect is secondary to the fall in serum estradiol levels and that VEGF may indirectly affect OHSS. In another study, the role of dopamine on angiogenesis was found to be brought about by factors such as the vascular permeability factor, vascular endothelial growth factor (VPF/VEGF) and they showed that dopamine acts at a non-toxic level and specifically with holds angiogenecity and permeability through VPF/VEGF ${ }^{(10)}$. Dopamine acts through D2 receptors and it causes VEGF-2 receptor endocytosis. This action of dopamine is specific for VPF/VEGF and does not affect other.

\section{CONCLUSION AND RECOMMENDATIONS}

- PCOS affects 5 to $10 \%$ of women of childbearing age and is the most common cause of anovulatory infertility in developed countries.

- Following In Vitro Fertilization (IVF) the overall incidence of OHSS is $0.6-14 \%$.

- Estradiol level has an important role in the prediction of OHSS.

- PCOS increases the number of infertile females to develop OHSS.

- Vaginal US and E2 level are important for diagnosis of OHSS.

- Overall, regarding the selective property of low dose cabergoline on VEGF control, it seems to be effective, convenient and safe drug which 
Ismaeil El-Garhy et al.

can be used together with coasting for prevention of OHSS.

- The present study showed that cabergoline did reduce the incidence of OHSS and the risk of hospitalization due to the lower occurrence of OHSS. These findings might be taken as evidence to suggest that cabergoline might be a valuable drug for the prevention and treatment of OHSS.

Further studies including large number of cases and for longer duration will further confirm the efficacy of cabergoline and coasting on prevention of OHSS.

\section{REFERENCES}

1) Nestler JE (2012): Metformin for the treatment of the polycystic ovary syndrome. N Engl J Med., 358: 4754.

2) Pelusi C and Pasquali R (2011): Polycystic ovary syndrome in adolescents. Pathophysiology and treatment implications. Treat Endocrinol., 2: 215-30.

3) Golan A, Ron-el R, Herman A, Soffer Y, Weinraub Z, Caspi E (2008): Ovarian hyperstimulation syndrome: an update review. Obstet Gynecol Surv., 44(6): 430-440.

4) Abou-Setta AM, Mansour R, Aboulghar M, Serour G, Amin Y(2013). Criteria of a successful coasting protocol for the prevention of severe ovarian hyperstimulation syndrome. Hum Reprod., 20(11): 3167-3172.

5) Englert Y, Delvigne A, Vekemans M, Lejeune B, Henlisz A et al. (1989): Is fresh or frozen semen to be used in in vitro fertilization with donor sperm? Fertil Steril., 51: 661-664.

6) Aboulghar MA and Mansour RT (2012): Ovarian hyperstimulation syndrome: classifications and critical analysis of preventive measures. Hum Reprod Update ,9:275-289.

7) Ata B, Seyhan A, Orhaner S, Urman B (2014): High dose cabergoline in management of ovarian hyperstimulation syndrome. Fertil Steril., 92: 1168.

8) Soares SR, Gómez R, Simón C et al. (2009): Targeting the vascular endothelial growth factor system to prevent ovarian hyperstimulation syndrome. Hum Reprod Update, 14: 321-33.

9) ESHRE/ASRM-Sponsored PCOS Consensus Workshop (2014): Group. Consensus on infertility treatment related to polycystic ovary syndrome. Fertil Steril., 89:505-22.

10) Basu S, Nagy JA, Pal S, Vasile E, Eckelhoefer IA, Bliss VS et al. (2001): The neurotransmitter dopamine inhibits angiogenesis induced by vascular permeability factor/ vascular endothelial growth factor. Nat Med., 7(5): 569-574.

11) Mansour R, Aboulghar $M$, Serour G, Amin $Y$, Abou- Setta AM (2005): Criteria of a successful coasting protocol for the prevention of severe ovarian hyperstimulation syndrome. Hum Reprod., 20(11): 3167-3172.

12) Alper MM, Smith LP, Sills ES (2009) Ovarian hyperstimulation syndrome: current views on pathophysiology, risk factors, prevention, and management. J Exp Clin Assist Reprod., 6: 3.

13) Delvigne A, Rozenberg S ( 2009): Preventive attitude of physicians to avoid OHSS in IVF patients. Hum Reprod., 16(12): 2491-2495.

14) Ulug U, Bahceci M, Erden HF, Shalev E, BenShlomo I ( 2002): The significance of coasting duration during ovarian stimulation for conception in assisted fertilization cycles. Hum Reprod., 17(2): 310313.

15) Whelan JG 3rd, Vlahos NF (2001): The ovarian hyperstimulation syndrome. Fertil Steril., 73(5):88396.

16) Egbase PE, Al-Sharhan M, Grudzinskas JG ( 2002): 'Early coasting' in patients with polycystic ovarian syndrome is consistent with good clinical outcome. Hum Reprod., 17(5): 1212-1216.

17) Benadiva CA, Davis O, Kligman I, Moomjy M, Liu HC, Rosenwaks Z (2000): Withholding gonadotropin administration is an effective alternative for the prevention of ovarian hyperstimulation syndrome. Fertil Steril., 67(4): 724-727.

18) García-Velasco JA, Zúñiga A, Pacheco A, Gómez R, Simón C, Remohí J et al. (2004): Coasting acts through downregulation of VEGF gene expression and protein secretion. Hum Reprod., 19(7): 1530-1538.

19) Ajonuma LC, Ajuonuma FO, Chukwu CL (2005): Coasting acts through downregulation of VEGF gene expression and protein secretion. Hum Reprod., 20: 574-575. 